\title{
Nonlinear soil-pile interaction induced by ground settlements: pile displacements and internal forces
}

\author{
A. FRANZA* , A. M. MARSHALL $\dagger$ and R. JIMENEZ $\ddagger$
}

\begin{abstract}
In urban areas, the construction of tunnels and deep-excavations beneath and near to pile foundations can be detrimental for the superstructure and the foundation. A two-stage continuum-based nonlinear soil-pile interaction model is presented in this paper for predicting the axial and flexural response of piles affected by ground movements. The model accounts for the effects of near-pile non-linear (hyperbolic) soil stiffness degradation and unloading effects. The approach is used to analyse the relationship between the pile axial response (both displacements and internal forces) and greenfield ground settlements for purely-frictional and floating piles in uniform ground. Both displacement and non-displacement piles are analysed by applying appropriate pre-excavation loading sequences. Results demonstrate the influence of initial safety factor, installation method, and capacity distribution (between shaft and base) on pile settlements and on critical tensile axial forces (both in terms of magnitude and depth). Dimensionless design charts are provided to estimate pile settlements and critical axial forces for the case of greenfield settlements that either increase or decrease linearly with depth. These charts provide a rational and more general framework to describe excavation-induced effects on piles than empirical methods.
\end{abstract}

KEYWORDS: Tunnels \& tunnelling, deep-excavations, settlement, pile, soil/structure interaction

\section{INTRODUCTION}

Engineers need to estimate the effects of ground movements resulting from tunnelling and deep-excavations (collectively referred to as excavations in this paper) on pile foundations. Previous research has extensively investigated the flexural response of piles to horizontal ground movements caused by urban excavations (among others, Chen et al. (1999); Mu et al. (2012); Poulos \& Chen (1997); Loganathan et al. (2001); Zhang et al. (2018)) and has provided design charts for estimating lateral deflections and internal moments. On the other hand, the pile response for problems dominated by ground settlements (e.g. tunnelling beneath piles, excavations deeper than pile base level) has not yet been fully characterised (Dias \& Bezuijen, 2015; Mair \& Williamson, 2014).

The soil-pile interaction problem is generally studied in terms of both pile settlements (associated with distortions and damage of buildings and infrastructure) and pile axial forces (linked with potential for pile cracking). Pile settlements are related to greenfield settlements $u_{z, g f}$ (when no pile is present) using the interaction level depth, $z_{i}$, which defines the soil depth where greenfield soil settlement (along the pile axis) matches that of the pile. Note that the interaction level is close (but not always identical) to the neutral level, which is the depth at which the pile shaft friction changes from negative to positive (Korff et al., 2016). In addition, the critical level depth, $z_{c}$, is defined as the depth at which the pile experiences the critical axial force, $N_{c}$, which is the maximum tensile or minimum compressive force along the pile after excavation (i.e. the combined result of pre-excavation pile head loading and excavation-induced ground movements). Note that, in this paper, a positive sign convention is used for tensile axial forces (e.g. $N_{c}>0$ for a tensile force).

As a first approximation, when dealing with a piled structure affected by excavation-induced ground settlements, a soilsingle pile interaction scenario is generally considered. This approach neglects the effects of pile-pile interactions and of pile load redistribution due to superstructure stiffness (i.e. it assumes a constant pile head load, $P$ ). For the case of urban excavations, studies have investigated qualitatively the relationship between interaction level $z_{i}$, initial pile safety factor

\footnotetext{
Manuscript received...

* ETSI Caminos, Universidad Politécnica de Madrid, Madrid, Spain. Corresponding author email: andreafranza@gmail.com

$\dagger$ Department of Civil Engineering, University of Nottingham, Nottingham, UK.

¥ ETSI Caminos, Universidad Politécnica de Madrid, Madrid, Spain.
} 


\section{SCOPE}

\section{MODEL}

$S F_{0}=Q_{t o t} / P$ (where $Q_{t o t}=Q_{b}+Q_{s}$ is the ultimate pile capacity given by the resistance of the shaft $Q_{s}$ and base $Q_{b}$ ), and subsurface greenfield settlements (among others, Basile (2014); Bel et al. (2015); Dias \& Bezuijen (2018); Franza \& Marshall (2019); Williamson et al. (2017b); Zhang et al. (2011b)). The interaction level is affected by the distribution of the ultimate pile capacity, which also defines the type of deep foundation: a purely-frictional pile with little base resistance, a floating pile with both shaft and base resistance, and an end-bearing pile with little shaft resistance (Mair \& Williamson, 2014; Korff et al., 2016). In practice, engineers commonly use design charts that relate pile head settlement to greenfield surface settlement depending on the location of the pile base (Kaalberg et al., 2005; Selemetas, 2005; Selemetas \& Standing, 2017), as shown in Figure 1. Alternatively, an empirical method can be used where pile settlement is taken as the greenfield settlement at (i) the surface, (ii) two-thirds the pile depth, and (iii) the pile base (i.e. $z_{i} / L_{p}=0,2 / 3,1$ ) for (i) purelyfrictional, (ii) floating, and (iii) end-bearing piles, respectively (Devriendt \& Williamson, 2011; Jacobsz et al., 2005). This method was used during the preliminary design stages of the Crossrail project (Williamson, 2014). Both of these approaches neglect the influence of $S F_{0}$. In fact, increased service loads $P$ (i.e. for a reduced $S F_{0}$ ) as well as soil non-linearity were found to increase excavation-induced pile settlements and, thus, $z_{i}$ (Basile, 2014; Dias \& Bezuijen, 2018; Williamson et al., 2017b; Zhang et al., 2011b). Korff et al. (2016) proposed a dimensionless framework to predict $z_{i}$ that accounted for the effect of $S F_{o}$ but was limited to the case of non-displacement single piles subjected to deep-excavation settlement profiles that decrease with depth. Tunnelling, however, is characterised by zones where both increasing and decreasing greenfield settlement profiles occur, as summarised in Figure 2.

The soil-pile interaction caused by ground movements also impacts pile internal forces. The main mechanisms relating to pile axial forces caused by excavation-induced ground movements have been studied (among others, Hong et al. (2015); Huang \& Mu (2012); Kitiyodom et al. (2005); Loganathan et al. (2001); Lee \& Chiang (2007); Soomro et al. (2015, 2017, 2019)). The excavation-induced variation of internal pile forces decreases with the magnitude of ground movements (Basile, 2014); in addition, piles with service loads approaching pile capacity with low initial safety factors suffer smaller additional excavation-induced axial forces than lightly loaded piles with high initial safety factors (Williamson et al., 2017a,b; Zhang et al., 2011b). In particular, there is the potential for tensile forces to develop within a pile located in the zone directly above a newly constructed tunnel (i.e. for linearly increasing greenfield ground movements), which was not considered by Korff et al. (2016). As discussed by Williamson (2014), pile cracking due to these tensile forces was a source of uncertainty for the field monitoring of piles affected by Crossrail tunnelling.

Finally, the construction/installation method (displacement or non-displacement piles) could impact the tunnel-pile interaction by influencing the pre-tunnelling distribution of mobilised soil reaction forces (in both undrained and drained conditions) as well as the effective stress level of the soil (in drained conditions). In particular, while displacement piles can have, prior to tunnelling, negative (downwards) friction along portions of their shaft (due to post-installation residual stresses in the soil and pile), and a base reaction force greater than the vertical service load $\left(Q_{b}>P\right)$, non-displacement piles have positive (upwards) shaft friction mobilised throughout and a base reaction force lower than the applied service load $\left(P>Q_{b}\right)$. Previous analytical studies mostly focused on non-displacement piles while this paper deals with both cases of displacement and non-displacement piles (referred to as $D P$ and $N P$, respectively).

A single pile with constant head load is studied using a nonlinear-elastoplastic continuum-based model to predict the response of piles to excavation-induced ground movements (where the term excavation refers to both tunnelling and deepexcavations). A parametric study is carried out for greenfield settlements with linearly increasing or decreasing profiles with depth, as shown in Figure 2. Dimensionless design charts are provided for preliminary interaction assessments, describing the main parameters affecting the settlements and post-tunnelling internal forces of displacement and non-displacement piles in uniform soil.

In this paper, a nonlinear continuum-based two-stage analysis method is adopted. The excavation is considered only in terms of induced greenfield ground movements with no change in the effective stress profile. The soil response to loading is not affected by the presence of the excavation. This is consistent with previous tunnel- and deep excavation-pile interaction analyses carried out using boundary element (BEM), finite element (FEM), and finite difference (FDM) methods adopting either continuum or Winkler mechanical models for the soil (Basile, 2014; Chen et al., 1999; Franza et al., 2019a; Loganathan et al., 2001; Williamson et al., 2017b; Korff et al., 2016; Zhang et al., 2011b, 2013). The soil is modelled as a homogeneous and isotropic half-space (referred to as a continuum) in which perfectly-plastic behaviour (e.g. due to slippage or soil failure) can occur at the pile-soil interface. Soil nonlinearity is assumed to be confined to the area near the pile shaft and base 
(referred to as near-pile), while the response describing interactions between different nodes along the pile (referred to as far-pile) is assumed linear elastic. The initial near-pile and far-pile response of the soil to loading depends on the soil's elastic parameters (i.e. initial Young's modulus, $E_{s, 0}$, and Poisson's ratio, $\nu_{s}$ ). These are described, respectively, by the diagonal and off-diagonal terms of the flexibility matrix obtained by integrating Mindlin's solutions along the pile boundary. The near-pile response is assumed either linear-elastic perfectly-plastic (EP solution) or nonlinear elastoplastic (NEP solution), as illustrated in Figures $3 \mathrm{a}$ and $3 \mathrm{~b}$.

To achieve the EP perfectly-plastic local soil behaviour shown in Figure 3a, sliders with limit forces were added at the pile-soil interface, while a near-pile soil stiffness of $E_{s, 0}$ was assumed for both loading an unloading. In the NEP method, in addition to sliders, the dependency of soil stiffness on the loading path (i.e. different stiffness for loading and unloading) and the soil stiffness degradation with relative soil-pile displacements was also considered, as displayed by Figure 3b. For loading and reverse loading, the tangent Young's modulus of the near-pile soil $E_{s}$ is decreased according to the DuncanChang hyperbolic law for which $E_{s}=E_{s, 0} \times\left(1-R_{f} f / f_{f}\right)^{2}$, which depends on the ratio between local soil reaction forces $f$ and the ultimate forces $f_{f}$, as well as the coefficient of hyperbolic stiffness reduction $R_{f}$, ranging between $0.8-1$ (Castelli \& Maugeri, 2002). This law is commonly adopted to predict pile response to external loading (Castelli \& Maugeri, 2002; Chow, 1986; Poulos, 1989) and has been used within other soil-pile interaction analyses (Basile, 2014; Zhang et al., 2011b, 2013). For unloading-reloading (paths AB' and C'D' in Figure 3b; i.e. for load increments causing a soil stress that is less than the largest positive or negative value experienced during its history), the local stiffness is assumed equal to the initial Young's modulus $E_{s, 0}$.

The effect of the hyperbolic coefficient $R_{f}$ on the stiffness degradation is shown schematically in Figure 3c. As a result of the plastic sliders, the elastic perfectly-plastic behaviour EP is given by $R_{f}=0$. For the NEP behaviour, an asymptotic trend associated with a negligible tangent stiffness is obtained at large deformations when $R_{f}=1$, whereas a more gradual stiffness degradation is given for $R_{f}<1$ up to the triggering of the slider limit force.

Finally, EP and NEP behaviour was only implemented in the vertical direction, whereas a linear elastic response (EL) was considered in the horizontal direction; this assumption has been shown to be reasonable based on the analysis of tunnelling problems (Basile, 2014). The proposed finite element (FEM) model was developed for groups of vertical piles of length $L_{p}$, diameter $d_{p}$, and Young's modulus $E$ with piles being modelled as Euler-Bernoulli beams embedded in a uniform continuum. This paper limits itself to excavation-single pile interaction; elevated caps, raft foundations, and superstructure contribution are neglected by assuming constant pile head loads during excavations. All these aspects can be accommodated within the proposed formulation following Franza et al. (2017); Leung et al. (2010) and Leung et al. (2017).

Considering the above assumptions, starting from the framework of Leung et al. (2010) and Franza \& DeJong (2019), the FEM model was developed by solving the set of expressions given in Equations (1)-(3). Equation (1) is the equilibrium equation; Equation (2) describes the near-pile stiffness; Equation (3) accounts for the sliders. The fully linear elastic solution (EL) is obtained from Equations (1) and (2) while assuming $R_{f}=0$; the elastic perfectly-plastic solution (EP) results from Equations (1)-(3) imposing $R_{f}=0$; and the nonlinear elastoplastic solution (NEP) is given by Equations (1)-(3) for $R_{f} \neq 0$.

$$
\begin{aligned}
& \left(\mathbf{S}+\mathbf{K}^{*}\right) \mathbf{u}=\mathbf{p}+\mathbf{K}^{*} \mathbf{u}^{\text {cat }}+\mathbf{K}^{*} \boldsymbol{\Lambda}^{*}\langle\mathbf{f}\rangle+\mathbf{K}^{*} \mathbf{u}^{i p} ; \mathbf{f}=(\mathbf{p}-\mathbf{S u}) \\
& \mathbf{K}^{*}=\mathbf{R}\left(\boldsymbol{\Lambda}-\mathbf{\Lambda}^{*}\right)^{-1} ; \quad R_{i i}= \begin{cases}1, & \text { for unloading } \\
\left(1-R_{f} \frac{f_{i}}{f_{f, i, d o w n}}\right)^{2}, & \text { for loading } \\
\left(1-R_{f} \frac{f_{i}}{f_{f, i, u p}}\right)^{2}, & \text { for reverse loading }\end{cases} \\
& \langle\mathbf{f}\rangle_{i}=f_{f, i, u p}<(\mathbf{P}-\mathbf{S u})_{i}<f_{f, i, \text { down }}
\end{aligned}
$$

where $\mathbf{u}$ is the displacement vector of the pile (consisting of three translational and three rotational degrees of freedom), $\mathbf{p}$ is the external loading vector at the pile head, $\mathbf{f}$ is the vector of forces applied by the foundation nodes to the soil (i.e. a vector containing the forces acting on the soil medium), $\mathbf{S}$ is the stiffness matrix of the pile foundation, $\mathbf{u}^{i p}$ is the plastic slider displacement vector, $\mathbf{u}^{\text {cat }}$ is the greenfield ground displacement vector, $\boldsymbol{\Lambda}$ is the linear elastic soil flexibility matrix relating the soil displacement field to the point of application of a force, $\boldsymbol{\Lambda}^{*}$ is the non-diagonal term of $\boldsymbol{\Lambda}$ (i.e. soil flexibility matrix without the main diagonal), and $\mathbf{K}^{*}$ is the local (near-pile) stiffness matrix of the soil (i.e. for no stiffness degradation, it is the inverse matrix of the diagonal term of $\boldsymbol{\Lambda}$ for the linear elastic behaviour in the near-pile soil). The terms $f_{f, i, u p}$ (negative) and $f_{f, i, d o w n}$ (positive) are the nodal limit forces for pile uplift and down-drag relative to the soil, which are given by the integration of the ultimate base, $q_{b, f}$, and shaft, $\tau_{f}$, stresses while considering no tensile capacity at 
the pile base. $\mathbf{R}$ is the near-pile stiffness reduction matrix, resulting in the initial linear elastic stiffness during unloading and hyperbolic stiffness degradation for loading and reverse loading. In the NEP solutions, unless stated otherwise, the values $R_{f}=1$ for the coefficient of hyperbolic near-pile soil stiffness degradation was used to be consistent with Korff et al. (2016).

The EL equations can be solved directly, whereas the EP and NEP expressions require an incremental and iterative procedure. Firstly, the equilibrium equation is solved for incremental variations of the load vector $\mathbf{p}$ while $\mathbf{u}^{\text {cat }}=0$. Secondly, for a constant load $\mathbf{p}$, greenfield settlements $\mathbf{u}^{\text {cat }}$ are incrementally applied. Excavation-induced effects (movements and forces) are given by the difference between the variables measured at the end of the first and second stage.

\section{MODEL VALIDATION}

To verify the developed EP model, results are compared against data from Basile (2014) for tunnelling adjacent to a single pile, which were obtained using the BEM PGROUPN program for perfectly-plastic soil behaviour with $R_{f}=0$. A pile with $L_{p}=25 \mathrm{~m}, d_{p}=0.5 \mathrm{~m}$, and $E=30 \mathrm{GPa}$ was affected by vertical and horizontal ground movements induced by a $6 \mathrm{~m}$ diameter tunnel with a depth to axis level of $20 \mathrm{~m}$ and a horizontal offset from the tunnel centreline to the pile axis of $4.5 \mathrm{~m}$. In this validation section, greenfield movements were estimated using the semi-analytical expressions of Loganathan \& Poulos (1998), with no external loads applied at the pile head, similar to Basile (2014). The considered soil was clay with $E_{s, 0}=24 \mathrm{MPa}$ and $\nu_{s}=0.5$, while the ultimate base and shaft resistances were given by $q_{b, f}=540 \mathrm{kPa}$ and $\tau_{f}=48 \mathrm{kPa}$ (assumed constant along the pile), respectively.

Figure 4 compares the results from the developed EP analysis method (tunnelling-induced pile displacements, deflections, axial forces, and bending moments) with the elastoplastic BEM PGROUPN results from Basile (2014); these outcomes are for an unloaded pile at low and high values of tunnel volume loss, $V_{l, t}=1$ and $5 \%$, respectively. For comparison, greenfield (GF) input movements are also shown; and results using the developed elastic EL model are also included for reference (validated in Franza et al. (2019b)). The agreement is satisfactory and, importantly, results show that by limiting the shaft friction in the EP solution significantly changes the EL results (i.e. tunnelling-induced settlements increased and axial forces decreased).

\section{TUNNELLING BENEATH PILES - INFLUENCE OF PARAMETERS}

To investigate the combined effects of the pile working conditions and the hyperbolic coefficient of stiffness degradation, the pile and soil considered in the previous section $\left(L_{p}=25 \mathrm{~m}, d_{p}=0.5 \mathrm{~m}, Q_{t o t}=1.99 \mathrm{MN}\right)$ was subjected to tunnelling from a $6 \mathrm{~m}$ diameter tunnel at a depth to axis level of $30 \mathrm{~m}$. The tunnel is assumed to be located either directly beneath the pile or at tunnel-pile offset of $15 \mathrm{~m}$. The greenfield inputs were again computed using Loganathan \& Poulos (1998).

Results of tunnelling-induced (Tun.ind.) settlements and forces as well as post-tunnelling (Post-tun.; i.e. the combined effects of initial pile loading and tunnelling-induced actions) pile axial force profiles are reported in Figures 5 and 6 for $S F_{0}=2 ; 100$ and $R_{f}=0 ; 0.75 ; 1$. Figure 5 shows outcomes for the offset pile for which greenfield settlements mostly decrease with depth, whereas Figure 6 displays the response of the pile directly above the tunnel where greenfield movements increase with depth. Note that pre-tunnelling axial forces are negligible for $S F_{0}=100$, hence post-tunnelling and tunnelling-induced forces match for this case. In addition, consider than tensile pile axial forces are positive in this paper.

For both tunnel offsets, the reduction in initial pile safety factor $S F_{0}$, associated with a greater pile head load, resulted in a slight increase in pile settlement, a reduction of the magnitude of tunnelling-induced forces, and a change in the shape of the axial force profile; these trends agree with conclusions of Williamson et al. (2017b). Figures 5 and 6 illustrate that the impact of the hyperbolic coefficient $R_{f}$ on tunnelling-induced displacements is minor, though higher values of $R_{f}$ tend to slightly reduce tunnelling-induced forces; this latter trend is reasonable considering the near-pile soil stiffness degradation associated with $R_{f}$.

Most of the tunnelling-induced forces in Figure 5 are compressive because the offset pile was subjected to greenfield settlements that decrease with depth. On the other hand, greenfield settlements that increase with depth can result in tensile forces due to tunnelling, as shown in Figure 6. However, Figure 6 indicates that the entire pile undergoes tensile post-tunnelling forces for $S F_{0}=100$ (see Figure $6 \mathrm{~d}$ ), whereas only the bottom part of the pile is under tension when $S F_{0}=2$ (see Figure 6c). Interestingly, the largest tensile critical force $N_{c}$ decreases in magnitude with the pile load $P$ (i.e. when $S F_{0}$ is reduced), whereas its location is closer to the pile tip for the highly loaded pile $\left(S F_{0}=2\right)$ than the lightly loaded pile $\left(S F_{0}=100\right)$.

In the following section, pile settlements and post-tunnelling tensile forces are investigated by assuming linearly increasing/decreasing settlements with depth. 


\section{PARAMETRIC RESULTS}

\section{Studied scenarios}

The NEP analyses in this section consider single piles of length $L_{p}=5 ; 20 \mathrm{~m}$, diameter $d_{p}=0.5 \mathrm{~m}$, and Young's modulus $E$ sufficiently large to simulate a rigid pile in a homogeneous soil with a Young's modulus $E_{s, 0}=24 \mathrm{MPa}$ and a Poisson's ratio $\nu_{s}=0.5$. The effect of pile compressibility on the considered interaction problem is minor for most practical scenarios, and the hyperbolic coefficient may be set to $R_{f}=1$ (Korff et al., 2016). Analyses were conducted using greenfield settlements that linearly increase or decrease with depth $z$, as shown in Figure 2, which can approximate excavation-induced settlements (e.g. Williamson et al. (2017b); Korff et al. (2016)).

Both purely-frictional and floating piles (labelled $F R$ and $F L$, respectively) were considered with $q_{b, f}$ either null or proportional to $\tau_{f}$ at the pile base. In this way, purely-frictional and floating piles are defined with respect to the mobilised reaction stresses for extremely large pile settlements. Two possible $\tau_{f}$ profiles along the pile axis were modelled: a constant (e.g. FR.con) and linearly increasing (e.g. FR.inc) profile of $\tau_{f}$ with $z$. In addition, to consider low shaft capacity piles due to interface disturbance or shaft coating, an additional analysis was performed for a coated pile with a reduced constant $\tau_{f}$ (CO.con). A summary of the considered cases is given in Table 1, where the first three scenarios are used as the 'main analyses' to demonstrate the salient features of the analysis results, and the outcomes of the remaining scenarios are included as supplemental data.

In this work, the ultimate capacity $Q_{\text {tot }}$ and the pile safety factor $S F_{0}$ are defined based on the very large pile settlements, potentially greater than $10 \% d_{p}$, needed to fully mobilise both $\tau_{f}$ and $q_{b, f}$, as shown in Figure 7a. Engineering judgement should be applied in specific scenarios to assess $Q_{\text {tot }}$. Therefore, use of the proposed design charts presented later is predicated on the existence of data which enables estimation of $Q_{t o t}$ and $S F_{0}$ for very large pile settlements (i.e. pile settlement of at least $10 \% d_{p}$ ). Furthermore, Figures $7 \mathrm{~b}$ and $7 \mathrm{c}$ sketch the pre-excavation loading sequence for non-displacement (NP; path $\mathrm{A} \rightarrow \mathrm{B})$ and displacement $(\mathrm{DP} ;$ path $\mathrm{A} \rightarrow \mathrm{D})$ piles.

In the parametric study presented here, $u_{z, g f}$ is modelled only in terms of $\Delta S$, which is the differential greenfield settlement between the surface and pile base. The surface greenfield settlement $\left(u_{z, g f, 0}\right.$, labelled $S_{0}$ here for consistency with Korff et al. (2016)) is $S_{0}=0$ in the performed analyses because a) the tunnel-pile interaction problem only depends on $\Delta S$, and b) a uniform greenfield settlement profile due to $S_{0}$ results in a pile settlement that is simply equal to the soil settlement, with no variation in the pile axial forces. For instance, from the definition of the interaction level depth, the excavation-induced pile settlement is $u_{\text {pile }}=S_{0}-z_{i} / L_{p} \times \Delta S$, whereas $z_{c}$ and $N_{c}$ are not dependent on $S_{0}$.

Similar to Korff et al. (2016), low and high levels of greenfield settlements were considered by analysing $u_{z, g f}$ characterised by a ratio $\Delta S / D_{z}=-10,-1,1,10$, where $\Delta S$ is the difference between greenfield displacement at the pile head and base (defined in Figure 2) and $D_{z}=Q_{t o t} / K_{0}$ is the ratio between the total pile capacity and the initial stiffness of the loadsettlement curve (illustrated in Figure 7a). For instance, a negative value of $\Delta S$ relates to piles above the tunnel where greenfield settlements increase with depth, whereas a positive $\Delta S$ relates to piles relatively far from the tunnel or adjacent to deep excavations, where greenfield settlements decrease with depth. On the other hand, the parameter $D_{z}$ is defined for the non-linear analysis (NEP) as the displacement obtained from the pile load-settlement curve $P-u_{z}$ (for no ground movements) by the intersection between the ultimate capacity $Q_{t o t}$ and the tangent to the initial portion of the curve with a slope equal to $K_{0}$. Alternatively, $D_{z}$ would be the settlement corresponding to the full mobilisation of pile capacity from pile loading results in an elastic-perfectly plastic (EP) analysis.

To generalise the outcomes from this work, results are presented using the dimensionless groups in Equation (4) used by Korff et al. (2016).

$$
S F_{0}=\frac{Q_{t o t}}{P}, \quad \frac{\Delta S}{D_{z}}, \quad \frac{\tau_{f, L_{p}}}{\tau_{f, 0}}, \quad Q_{r}=\frac{Q_{b}}{Q_{t o t}}, \quad \frac{E_{s}}{E_{p}}, \quad \frac{L}{d_{p}}, \quad \frac{D_{z}}{d_{p}}
$$

However, similar to Korff et al. (2016), the impact of $D_{z} / d_{p}$ was neglected (analyses for floating piles indicated that it had a minor impact on results), while the ratio $E_{s} / E_{p} \approx 0$ for the considered case of a relatively rigid pile. Because of the limited impact of the pile length-to-diameter ratio $L / d_{p}$, results presented here focus on the response of relatively long floating piles with $L / d_{p}=40$. Within this dimensionless representation, results for the floating piles FL (labelled as Qr05.con, Qr08.inc, and Qr40.con, where the numbers refer to the value of $Q_{r}$, i.e. the base capacity as a percentage of the total capacity) provide a description of the variability of all considered cases. Outcomes of the analyses for the remaining scenarios considering both $L / d_{p}=10$ and 40 are given in the supplemental data, where the 'supplemental label' in Table 1 is used to refer to each scenario.

\section{Parametric study and dimensionless charts}

Firstly, pile settlements relative to the greenfield movements are considered. The normalised interaction level $z_{i} / L_{p}$ is plotted against safety factor $S F_{0}$ in Figure 8. Engineers are familiar with analysing the relationship between pile and 
surface greenfield movements (see Figure 1); thus, the ratios $u_{\text {pile }} / u_{g f, 0}$ inferred from the data in Figure 8 are plotted in Figure 9 by assuming that $S_{0}=u_{g f, 0}=10 D_{z}$. Subsequently, using the same layout, the normalised critical depth $z_{c} / L_{p}$ and the ratio between critical axial forces and pull-out pile capacity $N_{c} / Q_{t}$ (positive sign assumed for tensile axial forces) are shown in Figures 10 and 11, respectively. $Q_{t}$ is mobilised by the reverse loading at the pile shaft, as illustrated in Figure 3 ; in this paper, identical values of $\tau_{f}$ are used for both loading and reverse loading and, thus, the magnitude of $Q_{t}$ and $Q_{s}$ are identical. Dashed and solid lines are used for decreasing (positive $\Delta S$; piles far from the tunnel or adjacent to deep excavations) and increasing (negative $\Delta S$; piles above the tunnel) values of $u_{z, g f}$ with $z$, respectively. Markers are used to distinguish between the pile installation methods: displacement (DP) and non-displacement (NP).

Results for both DP and NP piles in Figure 8 illustrate some general trends: [a] the variation of interaction level is within $z_{i} / L_{p}=0.4-0.8$ for both increasing and decreasing greenfield settlement profiles at high $S F_{0}$ (e.g. unloaded piles with $S F_{0} \geq 4$ ); [b] $z_{i} / L_{p}$ tends to zero (greenfield surface settlement) and unity (greenfield settlement at pile base level) for low $S F_{0}$ for decreasing and increasing greenfield settlements, respectively; and [c] the sensitivity of $z_{i} / L_{p}$ to the variation of safety factor is considerable within the range of $S F_{0}=1-3$. These trends agree qualitatively with the results of Korff et al. (2016) for non-displacement piles and a linearly decreasing $u_{z, g f}$. Importantly, because the largest tunnelling-induced values of $u_{z, g f}$ are generally at the location of the pile base and head for piles with their bases within and outside of the tunnel influence zone, respectively, the data in Figure 8 allow for a rational description of the empirical influence zones given by Selemetas (2005) and Kaalberg et al. (2005) (see Figure 1) while also accounting for soil and pile properties, pile load condition, and pile installation method.

The ratio $u_{\text {pile }} / u_{g f, 0}$ shown in Figure 9 highlights that pile settlements, normalised by the constant greenfield surface movement, increases with the pile service load $P$ (i.e. for decreasing $S F_{0}$ ) for both linearly increasing and decreasing greenfield movements. This agrees with centrifuge test outcomes of tunnelling beneath piles in clays, which indicated that the lower the value of $S F_{0}$, the greater the pile settlement, regardless of the offset of the pile from the tunnel (Williamson et al., 2017b). However, Figure 9 illustrates that the influence of $S F_{0}$ on $u_{p i l e} / u_{g f, 0}$ is significant only for steep greenfield movements with $\Delta S_{o} \approx S_{0}$, whereas the ratio $u_{\text {pile }} / u_{g f, 0}$ is about unity when $\Delta S_{o}<<S_{0}$. For the cases of $|\Delta S|=10$, the variation of $u_{\text {pile }} / u_{g f, 0}$ is most significant within the range of $S F_{0} \leq 3$, as was the case for the interaction level $z_{i} / L_{p}$.

In Figure 8, the linearly increasing $\tau_{f}$ resulting in $\tau_{f, L_{p}} / \tau_{f, 0}=3$ (QR08.inc) contributed to a slight increase in the value of $z_{i} / L_{p}$ (i.e. towards the pile base) compared to a constant $\tau_{f}$ associated with $\tau_{f, L_{p}} / \tau_{f, 0}=1$ (Qr05.con). Similarly, the effects of $\tau_{f, L_{p}} / \tau_{f, 0}$ on $u_{p i l e} / u_{g f, 0}$, normalised critical depth $z_{c} / L_{p}$, and axial force $N_{c} / Q_{t}$ is shown to be minor in Figures 9 , 10, and 11. Thus, the overall impact of $\tau_{f, L_{p}} / \tau_{f, 0}$ is secondary compared to the other dimensionless parameters within the investigated ranges.

With respect to the base capacity of the DP and NP piles with varying $Q_{r}=Q_{b} / Q_{\text {tot }}$ (Qr05.con and Qr40.con), the impact of the increase in the relative base capacity is notable: increasing $Q_{r}$ from $5 \%$ to $40 \%$ generally shifted $z_{i} / L_{p}$ towards the pile base (Figure 9), while it shifted the normalised force $N_{c} / Q_{t}$ towards negative (compressive) values for $S F_{0}<3$ (Figure 11). In particular, all considered piles with $Q_{r}=40 \%$ in Figure 11c are under compression along their entire length for $S F_{0}<2\left(N_{c} / Q_{c}<0\right)$, hence they would be at a low risk of cracking. This is not the case for the piles in Figure 11a and b subjected to increasing settlement with depth $(\Delta S<0)$, which have low values of $Q_{r}$ and may undergo tensile values of $N_{c} / Q_{t}$ for most values of $S F_{0}$. Furthermore, as confirmed by Figures S1-S4 in the supplemental data, results for purely-frictional FR and floating FL piles with $Q_{r}<10 \%$ are similar, hence the charts for Qr05.con and Qr08.inc are also applicable to purely-frictional FR piles when $Q_{b} / Q_{t o t}<10 \%$.

The location of the critical axial force along the pile is shown in Figure 10 using the normalised critical level depth $z_{c} / L_{p}$. Note that Figure 11 demonstrated that post-excavation tensile forces $\left(N_{c} / Q_{t}>0\right)$ are limited to the case of increasing greenfield settlements with depth $(\Delta S<0)$; decreasing settlements with depth $(\Delta S>0)$ result in compressive excavationinduced axial forces for all cases $\left(N_{c} / Q_{t}<0\right)$. Consequently, a critical level depth $z_{c}$ is not presented for $\Delta S>0$. Figure 10 shows that $z_{c}$ moves towards the base of the pile for decreasing $S F_{0}$ and reaches $z_{c} / L_{p}=1$ at $S F_{0} \approx 1.5$ for all cases (the rate of change is notable between $S F_{0}=1.5$ and 3 ). Also, in general, the DP values of $z_{c} / L_{p}$ are lower (towards the pile head) than for NP for a given value of $\Delta S / D_{z}$. This is due to the presence of residual (post-loading and pre-excavation) compressive axial forces near the pile mid-depth region for DP piles.

Focusing again on the critical case of $\Delta S<0$ which can produce tensile axial forces, Figure 11 shows that, as a general trend, the pile critical axial forces $N_{c} / Q_{t}$ increase with the settlement rate $\Delta S / D_{z}=-1 \rightarrow-10$, particularly for $S F_{0}>2$. For typical design values of $S F_{0}=2-3, N_{c} / Q_{t} \approx 25 \%$, whereas for extremely large values of $S F_{0}$, the upper-bound of $N_{c} / Q_{t}$ approaches $40 \%$. For low safety factors $\left(S F_{0}<1.5\right), N_{c} / Q_{t}$ values are either close to zero (when $\left.Q_{r} \approx 0\right)$ or negative (when $Q_{r}>0$ ), while $z_{c} / L_{p}=1$ in these cases. The fact that the pile undergoes no tensile axial forces for low safety factors is in agreement with previous research that indicated negligible variation in pile axial forces due to tunnelling when the service load is close to the total capacity (e.g. Zhang et al. (2011a)). This phenomenon occurs because, prior to the ground 
movements, the application of a service load $P$ of magnitude approaching the total capacity $Q_{t o t}$ mobilises most of the soil capacity and causes a degradation of the near-pile tangent soil stiffness (i.e. the reduction factor $R_{i i}$ is close to zero). Therefore, excavation-induced forces $\mathbf{K}^{*} \mathbf{u}^{\text {cat}}$, which relate to $R_{i i}$, are negligible in magnitude for very low safety factors, while $N_{c} / Q_{t}$ depends mostly on the head load $P$.

Results in Figures 8, 10, and 11 show that the normalised settlement magnitude $\Delta S / D_{z}$ affects the relative response, in terms of pile settlement and axial behaviour, of displacement (DP) and non-displacement (NP) piles. The difference between DP and NP outcomes is particularly obvious for $\left|\Delta S / D_{z}\right|=1$ (except for $S F_{0}=1.1$, which is the lowest considered safety factor), while the response of DP and NP piles is similar for $\left|\Delta S / D_{z}\right|=10$. The reasons for these trends are summarised as follows.

- Prior to ground movements $\Delta S$, displacement piles DP have an unloading soil stiffness as well as residual stresses. For DP with $S F_{0}>1.5$, the final loading step D is far from the intermediate step B (that mobilised the ultimate capacity) in Figure 7c. For small ground movements $\left(\left|\Delta S / D_{z}\right|=1\right)$ the pile responds with its tangent re-loading stiffness equal to $E_{s, 0}$ (along the segment B'-A in Figure $3 \mathrm{~b}$ ). Thus, the value of $z_{i} / L_{p}$ of the DP pile does not vary much from the average settlement $z_{i} / L_{p} \approx 0.5$ that is typical for an elastic EL analysis. However, $z_{i} / L_{p}$ shifts towards the pile head or base for greater greenfield movements (see $\left|\Delta S / D_{z}\right|=10$ ) because the soil transitions from the re-loading stiffness to the further loading stiffness (A-B in Figure 3b, where tangent stiffness $E$ is given by $E_{s}$ reduced by $R_{i i}$ ) and pile settlements approach maximum greenfield settlements $\left(z_{i} / L_{p}\right.$ tends to 0 or 1$)$ rather than the average settlement $\left(z_{i} / L_{p} \approx 0.5\right)$.

- For DP piles with $S F_{0}=1.1$ (the lowest considered safety factor), the response is close to NP behaviour because the final loading step D is close to the intermediate step B that mobilised the ultimate capacity. Thus, the range of high re-loading stiffness (along the segment B'-A in Figure $3 \mathrm{~b}$ ) is rather small and the state of further loading (A-B in Figure $3 \mathrm{~b}$ ) is reached for low values of greenfield ground movements.

- For both NP and DP piles with large values of $\left|\Delta S / D_{z}\right|=10$, the excavation-induced relative soil-pile displacements dominate and, thus, the pile loading path prior to excavation has little effect.

\section{Example application of design charts}

To illustrate the use of the proposed design charts, the case Qr05.con of a floating non-displacement pile $\left(d_{p}=0.5 \mathrm{~m}\right.$, $L=20 \mathrm{~m}$ ) embedded in a uniform ground with a representative initial stiffness $E_{s, 0}=24 \mathrm{MPa}$ and undrained shear strength of $60 \mathrm{kPa}$ is considered. From the geometry and soil strength parameters it is estimated that $\tau_{f}=60 \mathrm{kPa}, q_{b, f}=540 \mathrm{kPa}$, $Q_{b}=0.11 \mathrm{MN}, Q_{t} \approx Q_{s}=1.88 \mathrm{MN}$, and $Q_{t o t}=1.99 \mathrm{MN}$. The value of $D_{z}=9 \mathrm{~mm}$ is inferred from $Q_{t o t}, L / d_{p}$ and $E_{s}$. If an elastic soil-pile interaction model is not available, engineers may estimate $D_{z}$ from the load $Q_{t o t}$ and the displacement influence factor charts of Poulos \& Davis (1968).

The pile is subjected to a linearly increasing profile of greenfield settlements where settlement at the pile head and tip are, respectively, 12 and $21 \mathrm{~mm}$; therefore, $S_{0}=12 \mathrm{~mm}$ and $\Delta S=-9 \mathrm{~mm}$. The main dimensionless groups representative of the given scenario are $Q_{r}=5 \%, S F_{0}, \tau_{f, L_{p}} / \tau_{f, 0}=1, \Delta S / D_{z}=-1$.

To estimate pile settlement, depth, and magnitude of post-tunnelling critical tensile forces, the solid red (lighter shade in greyscale) curves with no markers in Figures 8-11 are used. First, consider a pile head load of $P=664 \mathrm{kN}$, for which $S F_{0}=3$. Using this, the charts give $z_{i} / L_{p}=0.65, z_{c} / L_{p}=0.83$, and $N_{c} / Q_{t}=0.025$. Thus, the pile settlement is $u_{\text {pile }}=S_{0}-z_{i} / L_{p} \times \Delta S=17.9 \mathrm{~mm}$; the normalised critical depth is $z_{c}=0.83 \times L_{p}=16.6 \mathrm{~m}$; and the maximum posttunnelling tensile force is $N_{c}=0.025 \times Q_{t}=47 \mathrm{kN}$. Second, consider an unloaded pile $\left(S F_{0} \approx 100\right)$ for which $z_{i} / L_{p}=0.53$, $z_{c} / L_{p}=0.55, N_{c} / Q_{t}=0.145$. It follows that pile settlement is $u_{\text {pile }}=16.8 \mathrm{~mm}$, normalised critical depth is $z_{c}=11 \mathrm{~m}$, and maximum post-tunnelling tensile force is $N_{c}=273 \mathrm{kN}$. 


\section{respectively. pile cracking.}

CONCLUSIONS

In this paper, a nonlinear two-stage continuum-based finite element model was proposed to study the problem of tunneland deep excavation-pile interaction. A hyperbolic soil model for the near-pile stiffness degradation was incorporated that also considers the effects of pile unloading. The model was validated against boundary element method results based on an assumed elastic perfectly-plastic soil behaviour. Pile ultimate capacity was defined based on predicted loads required for extremely large pile settlements.

Analyses were carried out to evaluate the settlements and internal forces of purely-frictional and floating piles in a uniform ground for different levels of greenfield ground settlements. Greenfield settlements that increase linearly with depth were used to replicate piles located above tunnels, whereas linearly decreasing greenfield settlements were used for piles more distant from the tunnel or adjacent to a deep excavation. The following provides a summary of the main outcomes of the research, where the term excavation is used to imply both tunnels and deep excavations.

- Results illustrated the way in which pile safety factor can increase or decrease excavation-induced pile settlements and tensile forces (the latter only for the case of greenfield settlements increasing with depth), confirming the results of previous works characterised by nonlinear trends due to the interaction mechanisms. On the other hand, for this nonlinear soil-pile interaction model, it was shown that the installation method can significantly affect the axial pile response to ground movements, but only for low levels of excavation-induced settlements.

- The obtained variability of the interaction level (depth at which the affected pile settlement matches the greenfield value) and critical level (depth at which the maximum post-tunnelling tensile axial force occurs) was extremely wide for both purely-frictional and floating piles. For standard design working loads and unloaded piles, the computed maximum values of tensile post-tunnelling axial forces were $25 \%$ and $40 \%$ of the pull-out (shaft) pile capacity,

- The nonlinear soil-pile interaction model results are suggested for preliminary design evaluations. Dimensionless charts were provided to allow designers to estimate both settlements and critical (tensile) axial forces of piles affected by excavations, hence providing the first attempt to provide a rational framework that characterises both displacements and internal forces for piles affected by tunnels and deep excavations. The charts account for the normalised greenfield settlement level (high and low); relative base capacity (between zero and $40 \%$ of the total capacity); ultimate shaft friction (constant and linearly increasing with depth); pile safety factor (between 1 and 100), and installation method (displacement and non-displacement piles). In particular, the proposed charts are more comprehensive than empirical influence zones available in the literature (Kaalberg et al., 2005; Selemetas, 2005), which relate only to the pile base-totunnel relative location and do not provide quantitative insights as to the effect of excavations on piles. Furthermore, in agreement with Korff et al. (2016), results demonstrate that available empirical methods which assume that the interaction level occurs at the surface or at two-thirds of the pile length (for purely-frictional and floating piles, respectively) may be misleading. Finally, note that these design charts are applicable only for elastic pile behaviour; if a pile is susceptible to cracking and softening, then the charts can only be applied up to a state associated with

Finally, the proposed simplified model has limitations, particularly for predicting the response of displacement piles. Note that this paper dealt with the effects of ground movements while neglecting the impact of effective stress variations (due to the excavations or from pile installation), which can alter the tunnel-pile interactions, particularly for displacement piles in sand (Marshall \& Mair, 2011). Further work is also needed to better characterise the effects of tunnelling while considering installation processes (e.g. driven, jacked, screwed piles), and pile tip geometry (e.g. open/closed-ended).

\section{ACKNOWLEDGEMENTS}

This project has received funding from the European Union's Horizon 2020 research and innovation programme under the Marie Sklodowska-Curie grant agreement No 793715.

\section{SUPPLEMENTAL DATA}




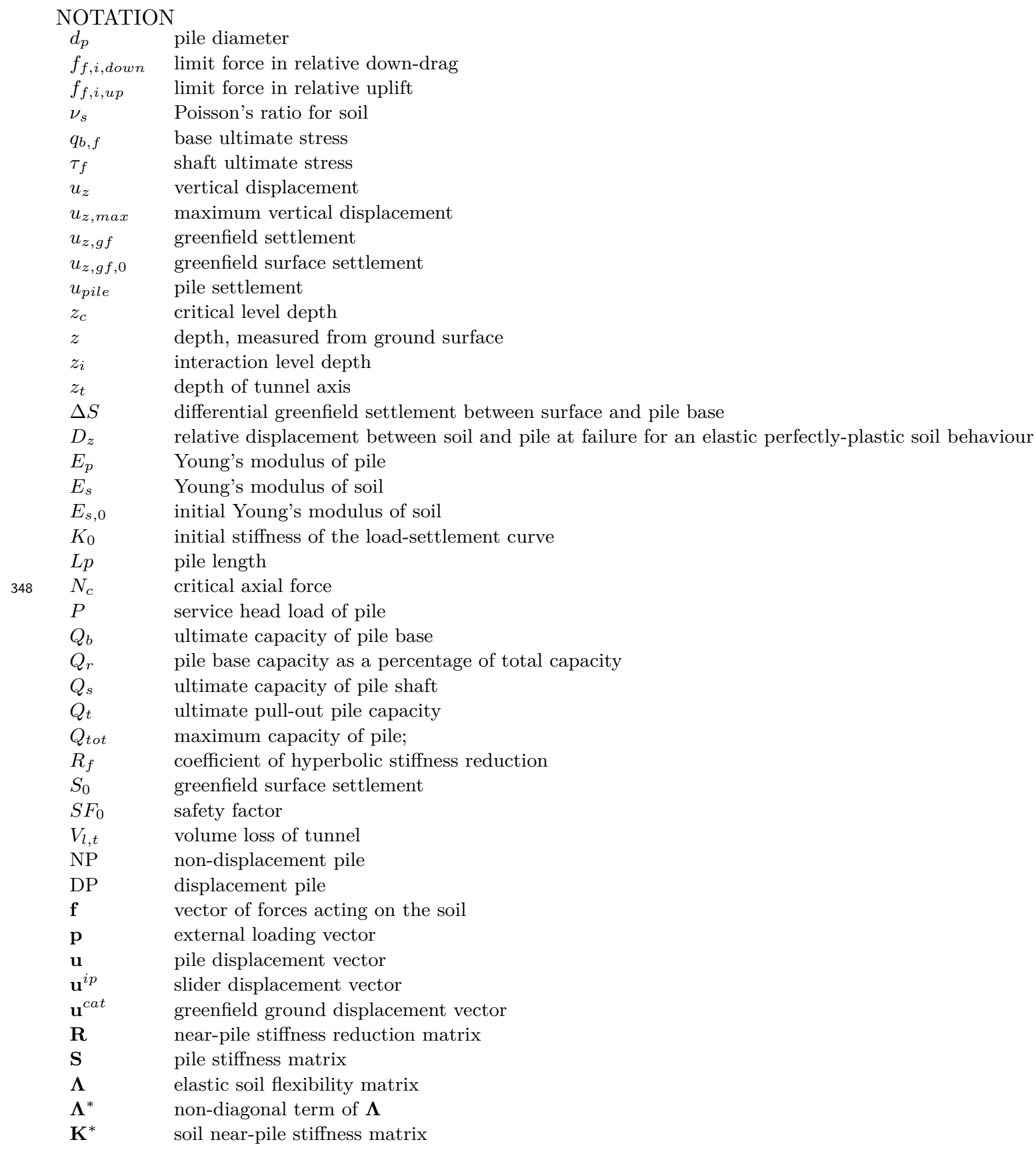

\section{REFERENCES}

Basile, F. (2014). Effects of tunnelling on pile foundations. Soils and Foundations 54, No. 3, 280-295, doi:10.1016/j.sandf.2014.04.004. Bel, J., Branque, D., Wong, H., Viggiani, G. \& Losacco, N. (2015). Experimental study on a 1g reduced scale model of TBM: impact of tunnelling on piled structures. In Proceedings of the XVI European Conference on Soil Mechanics and Geotechnical Engineering, ECSMGE 2015, pp. 413-418.

Castelli, F. \& Maugeri, M. (2002). Simplified Nonlinear Analysis for Settlement Prediction of Pile Groups. Journal of Geotechnical and Geoenvironmental Engineering 128, No. 1, 76-84, doi:10.1061/(ASCE)1090-0241(2002)128:1(76).

Chen, L. T., Poulos, H. G. \& Loganathan, N. (1999). Pile responses caused by tunneling. Journal of Geotechnical and Geoenvironmental Engineering 125, No. 2-3, 207-215.

Chow, Y. K. (1986). Analysis of vertically loaded pile groups. International Journal for Numerical and Analytical Methods in Geomechanics 10, No. 1, 59-72, doi:10.1002/nag.1610100105.

Devriendt, M. \& Williamson, M. (2011). Validation of methods for assessing tunnelling-induced settlements on piles. Ground Engineering, No. March, 25-30.

Dias, T. \& Bezuijen, A. (2018). Pile tunnel interaction: Pile settlement vs Ground settlements. In ITA World Tunnel Congress 2018 - The role of underground space in building future sustainable cities, Dubai, United Arab Emirates.

Dias, T. G. S. \& Bezuijen, A. (2015). Data Analysis of Pile Tunnel Interaction. Journal of Geotechnical and Geoenvironmental Engineering 141, No. 12, 04015051, doi:10.1061/(ASCE)GT.1943-5606.0001350.

Franza, A. \& DeJong, M. J. (2019). Elastoplastic solutions to predict tunneling-induced load redistribution and deformation of surface structures. Journal of Geotechnical and Geoenvironmental Engineering 145, No. 4, 04019007, doi:10.1061/(ASCE)GT.1943-5606. 0002021. 
Franza, A. \& Marshall, A. M. (2019). Centrifuge and real-time hybrid testing of tunneling beneath piles and piled buildings. Journal of Geotechnical and Geoenvironmental Engineering 145, No. 3, 04018110, doi:10.1061/(ASCE)GT.1943-5606.0002003.

Franza, A., Marshall, A. M., Haji, T., Abdelatif, A. O., Carbonari, S. \& Morici, M. (2017). A simplified elastic analysis of tunnel-piled structure interaction. Tunnelling and Underground Space Technology 61, No. Jan, 104-121, doi:10.1016/j.tust.2016.09.008.

Franza, A., Marshall, A. M. \& Jimenez, R. (2019a). An analysis method for the effects of tunnelling on loaded non-displacement piles. In XVI Panamerican Conference on Soil Mechanics and Geotechnical Engineering.

Franza, A., Marshall, A. M. \& Jimenez, R. (2019b). Elastic analysis of tunnelling beneath capped pile groups. In Proceedings of the XVII ECSMGE-2019: Geotechnical Engineering foundation of the future.

Hong, Y., Soomro, M. \& Ng, C. (2015). Settlement and load transfer mechanism of pile group due to side-by-side twin tunnelling. Computers and Geotechnics 64, No. March, 105-119, doi:10.1016/j.compgeo.2014.10.007.

Huang, M. \& Mu, L. (2012). Vertical response of pile raft foundations subjected to tunneling-induced ground movements in layered soil. International Journal for Numerical and Analytical Methods in Geomechanics 36, No. 8, 977-1001, doi:10.1002/nag.1035.

Jacobsz, S. W., Bowers, K. H., Moss, N. A. \& Zanardo, G. (2005). The effects of tunnelling on piled structures on the CTRL. In Proceedings of the 5th International Conference of TC28 of the ISSMGE on Geotechnical Aspects of Underground Construction in Soft Ground (Bakker, K. J., Bezuijen, A., Broere, W. \& Kwast, E., eds.), Amsterdam, the Netherlands: Balkema, Leiden, Netherlands, pp. 115-121.

Kaalberg, F. J., Teunissen, E. A. H., van Tol, A. F. \& Bosch, J. W. (2005). Dutch research on the impact of shield tunnelling on pile foundations. In Proceedings of the 5th International Conference of TC28 of the ISSMGE on Geotechnical Aspects of Underground Construction in Soft Ground (Bakker, K. J., Bezuijen, A., Broere, W. \& Kwast, E. A., eds.), Amsterdam, the Netherlands: Taylor \& Francis - Balkema, pp. 123-131.

Kitiyodom, P., Matsumoto, T. \& Kawaguchi, K. (2005). A simplified analysis method for piled raft foundations subjected to ground movements induced by tunnelling. International Journal for Numerical and Analytical Methods in Geomechanics 29, No. 15, 1485-1507, doi:10.1002/nag.469.

Korff, M., Mair, R. J. \& Tol, F. A. F. V. (2016). Pile-Soil Interaction and Settlement Effects Induced by Deep Excavations. Journal of Geotechnical and Geoenvironmental Engineering 142, No. 8, 04016034.

Lee, C.-J. J. \& Chiang, K.-H. H. (2007). Responses of single piles to tunneling-induced soil movements in sandy ground. Canadian Geotechnical Journal 44, No. 10, 1224-1241, doi:10.1139/T07-050.

Leung, Y. F., Klar, A. \& Soga, K. (2010). Theoretical Study on Pile Length Optimization of Pile Groups and Piled Rafts. Journal of Geotechnical and Geoenvironmental Engineering 136, No. 2, 319-330, doi:10.1061/(ASCE)GT.1943-5606.0000206.

Leung, Y. F. A., Klar, A., Soga, K. \& Hoult, N. A. (2017). Superstructure-foundation interaction in multi-objective pile group optimization considering settlement response. Canadian Geotechnical Journal 54, No. 10, 1408-1420.

Loganathan, N. \& Poulos, H. G. (1998). Analytical prediction for tunneling-induced ground movements in clays. Journal of Geotechnical and Geoenvironmental Engineering 124, No. 9, 846-856, doi:10.1061/(ASCE)1090-0241(1998)124:9(846).

Loganathan, N., Poulos, H. G. \& Xu, K. J. (2001). Ground and pile-group responses due to tunnelling. Soils and Foundations 41, No. $1,57-67$.

Mair, R. \& Williamson, M. (2014). The influence of tunnelling and deep excavation on piled foundations. In Proceedings of the 8th International Symposium on Geotechnical Aspects of Underground Construction in Soft Ground (Yoo, C., Park, S.-W., Kim, B. \& Ban, H., eds.), Seoul, South Korea: Taylor and Francis - Balkema, pp. 21-30, doi:10.1201/b17240-6.

Marshall, A. M. A. \& Mair, R. R. J. (2011). Tunneling beneath driven or jacked end-bearing piles in sand. Canadian Geotechnical Journal 48, No. 12, 1757-1771, doi:10.1139/t11-067.

Mu, L., Huang, M. \& Finno, R. J. (2012). Tunnelling effects on lateral behavior of pile rafts in layered soil. Tunnelling and Underground Space Technology 28, 192-201, doi:10.1016/j.tust.2011.10.010.

Poulos, H. G. (1989). Pile behaviour - theory and application. Géotechnique 39, No. 3, 365-415.

Poulos, H. G. \& Chen, L. T. (1997). Pile response due to excavation-induced lateral soil movement. Journal of Geotechnical and Geoenvironmental Engineering 123, No. 2, 94-99, doi:10.1061/(ASCE)1090-0241(1997)123:2(94).

Poulos, H. G. \& Davis, E. H. (1968). Settlement behaviour of single axially loaded incompressible piles and piers. Géotechnique 18, No. 3, 351-371.

Selemetas, D. (2005). The response of full-scale piles and piled structures to tunnelling. Ph.D. Thesis, Cambridge University

Selemetas, D. \& Standing, J. R. (2017). Response of Full-Scale Piles to EPBM Tunnelling in London Clay. Géotechnique 67, No. 9, 823-836, doi:10.1680/jgeot.SIP17.P.126.

Soomro, M. A., Hong, Y., Ng, C. W. W., Lu, H. \& Peng, S. (2015). Load transfer mechanism in pile group due to single tunnel advancement in stiff clay. Tunnelling and Underground Space Technology 45, No. January, 63-72, doi:10.1016/j.tust.2014.08.001.

Soomro, M. A., Mangnejo, D. A., Bhanbhro, R., Memon, N. A. \& Memon, M. A. (2019). 3D finite element analysis of pile responses to adjacent excavation in soft clay: Effects of different excavation depths systems relative to a floating pile. Tunnelling and Underground Space Technology 86, No. April, 138-155, doi:10.1016/j.tust.2019.01.012.

Soomro, M. A., Ng, C. W., Liu, K. \& Memon, N. A. (2017). Pile responses to side-by-side twin tunnelling in stiff clay: Effects of different tunnel depths relative to pile. Computers and Geotechnics 84, 101-116, doi:10.1016/j.compgeo.2016.11.011.

Williamson, M. G. (2014). Tunnelling effects on bored piles in clay. Ph.D. Thesis, Cambridge University .

Williamson, M. G., Elshafie, M. Z. E. B., Mair, R. J. \& Devriendt, M. D. (2017a). Open-face tunnelling effects on non-displacement piles in clay - part 1: centrifuge modelling techniques. Géotechnique 67, No. 11, 983-1000, doi:10.1680/jgeot.sip17.P.119.

Williamson, M. G., Mair, R. J., Devriendt, M. D. \& Elshafie, M. Z. E. B. (2017b). Open-face tunnelling effects on non-displacement piles in clay - part 2: tunnelling beneath loaded piles and analytical modelling. Géotechnique 67, No. 11, 1001-1019, doi: 10.1680/jgeot.SIP17.P.120.

Zhang, R., Zheng, J., Pu, H. \& Zhang, L. (2011a). Analysis of excavation-induced responses of loaded pile foundations considering unloading effect. Tunnelling and Underground Space Technology 26, No. 2, 320-335, doi:http://dx.doi.org/10.1016/j.tust.2010.11. 003.

Zhang, R. J., Zheng, J. J. \& Yu, S. (2013). Responses of piles subjected to excavation-induced vertical soil movement considering unloading effect and interfacial slip characteristics. Tunnelling and Underground Space Technology 36, 66-79, doi:10.1016/j.tust. 2013.02.005.

Zhang, R. J., Zheng, J. J., Zhang, L. M. \& Pu, H. F. (2011b). An analysis method for the influence of tunneling on adjacent loaded pile groups with rigid elevated caps. International Journal for Numerical and Analytical Methods in Geomechanics 35, No. 18, 1949-1971, doi:10.1002/nag.

Zhang, Z., Huang, M., Xu, C., Jiang, Y. \& Wang, W. (2018). Simplified solution for tunnel-soil-pile interaction in Pasternak's foundation model. Tunnelling and Underground Space Technology 78, 146-158, doi:10.1016/j.tust.2018.04.025. 


\section{LIST OF FIGURES}

1 Relationships between pile and greenfield surface settlements depending on the pile base location (Selemetas,

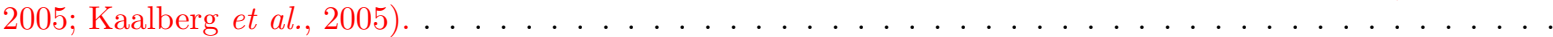

2 Sketch of (a) tunnel- and (b) deep excavation-pile interaction problems as well as greenfield ground movement profiles $\left(u_{z, g f}\right)$ assumed in this work. . . . . . . . . . . . . . . . . . . . . . . . . . . . .

3 (a) Linear-elastic perfectly-plastic (EP) and (b) nonlinear elastoplastic (NEP) behaviour of the interface and the near-pile soil for $R_{f}=1$ (follow the letter order for loading paths). (c) Influence of coefficient $R_{f}$ of hyperbolic stiffness reduction. . . . . . . . . . . . . . . . . . . . . . . . . . . .

4 Tunnelling-induced axial and flexural response of an unloaded single pile. . . . . . . . . . . . . . . . . . .

5 Axial response for tunnel-pile offset of 15m: (a)-(b) tunnelling-induced settlements; (c)-(d) tunnelling-induced and post-tunnelling force profiles. . . . . . . . . . . . . . . . . . . . . . . . . . . . . .

6 Axial response for tunnel-pile offset of zero: (a)-(b) tunnelling-induced settlements; (c)-(d) tunnelling-induced and post-tunnelling force profiles. . . . . . . . . . . . . . . . . . . . . . . . . . . .

7 Conceptual sketches of pre-tunnelling pile loading: (a) pile head load-settlement curve and the definition of the settlement $D_{z}$; pre-excavation loading sequence of (b) non-displacement and (c) displacement piles. . . 8 Normalised interaction level depth $\left(z_{i} / L_{p}\right)$ for varying pile safety factor and greenfield profiles. . . . . . .

9 Ratio between pile and greenfield surface settlements: inferred from Figure 8 by assuming $S_{0}=10 D_{z}$. . .

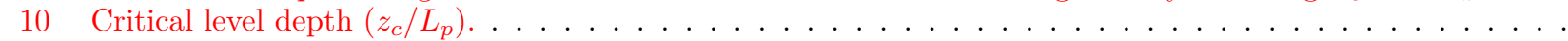

11 Post-tunnelling critical axial force $\left(N_{c} / Q_{t}\right)$. . . . . . . . . . . . . . . . . . . . . . . . . . . . .

S1 [Supplemental data] Normalised interaction level depth $\left(z_{i} / L_{p}\right)$. . . . . . . . . . . . . . . . . . . .

S2 Supplemental data] Ratio between pile and greenfield surface settlements..................

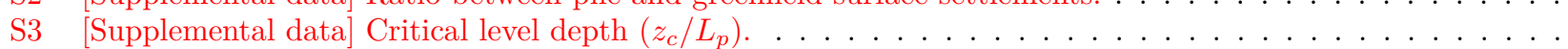

S4 [Supplemental data] Post-tunnelling critical axial force $\left(N_{c} / Q_{t}\right)$. . . . . . . . . . . . . . . . . . . . 


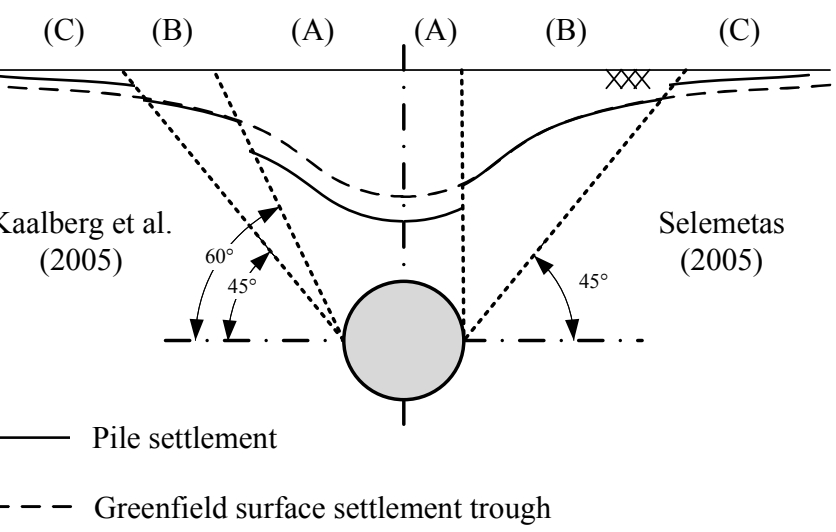

Fig. 1. Relationships between pile and greenfield surface settlements depending on the pile base location (Selemetas, 2005; Kaalberg et al., 2005).

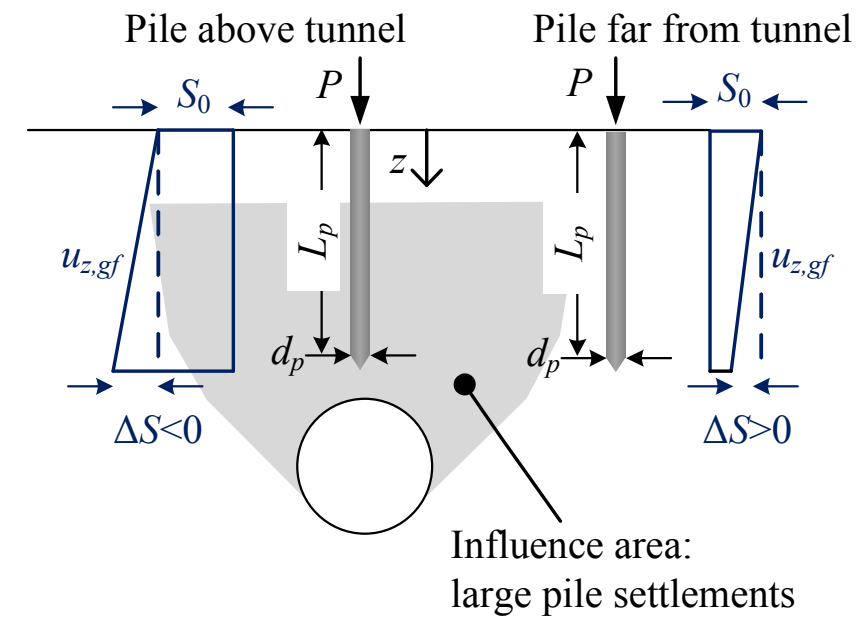

(a)

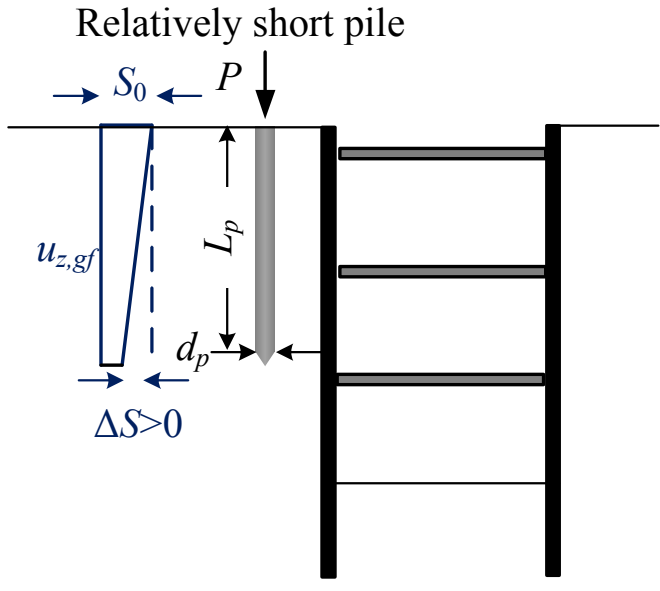

(b)

Fig. 2. Sketch of (a) tunnel- and (b) deep excavation-pile interaction problems as well as greenfield ground movement profiles $\left(u_{z, g f}\right)$ assumed in this work.

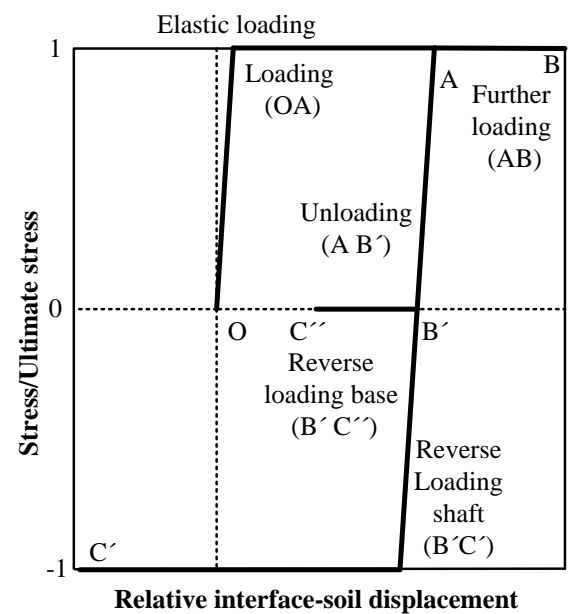

(a)

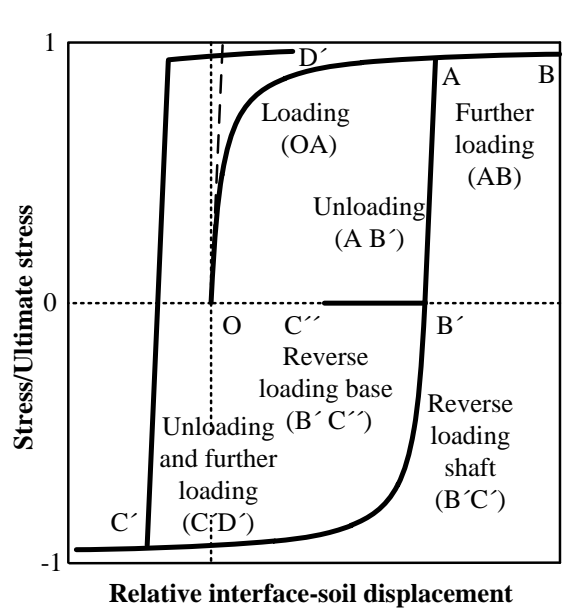

(b)

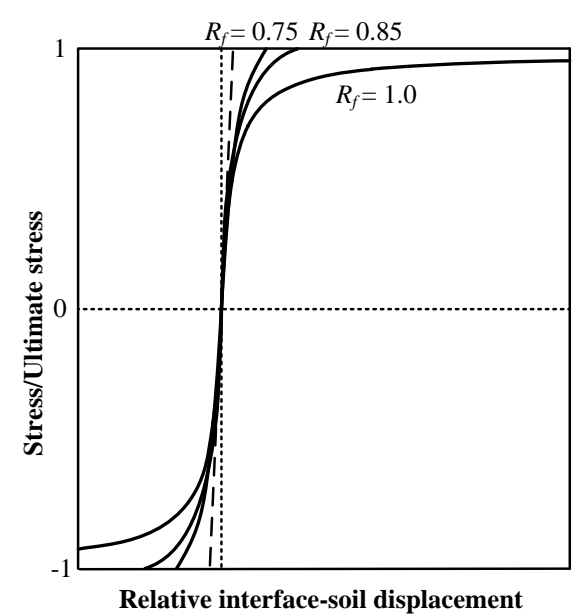

(c)

Fig. 3. (a) Linear-elastic perfectly-plastic (EP) and (b) nonlinear elastoplastic (NEP) behaviour of the interface and the near-pile soil for $R_{f}=1$ (follow the letter order for loading paths). (c) Influence of coefficient $R_{f}$ of hyperbolic stiffness reduction. 

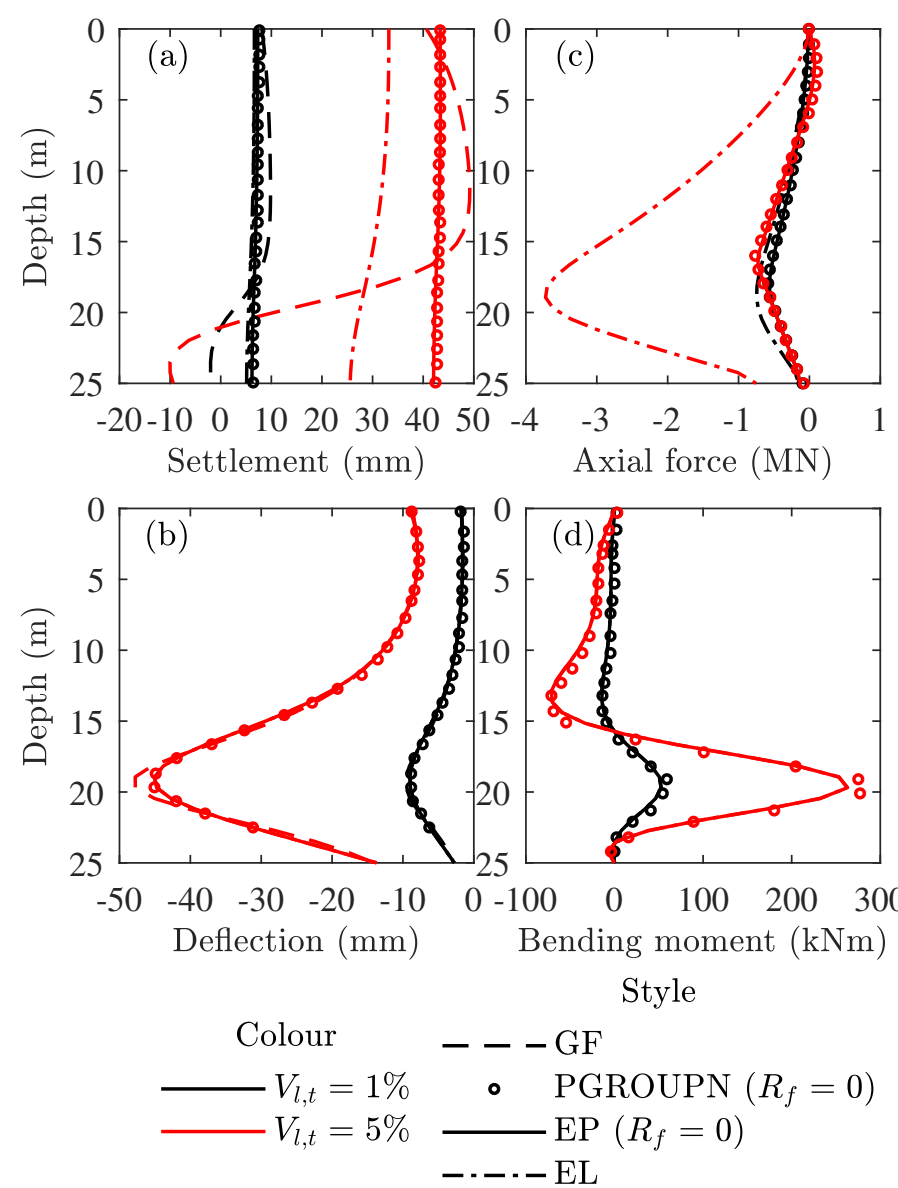

Fig. 4. Tunnelling-induced axial and flexural response of an unloaded single pile. 

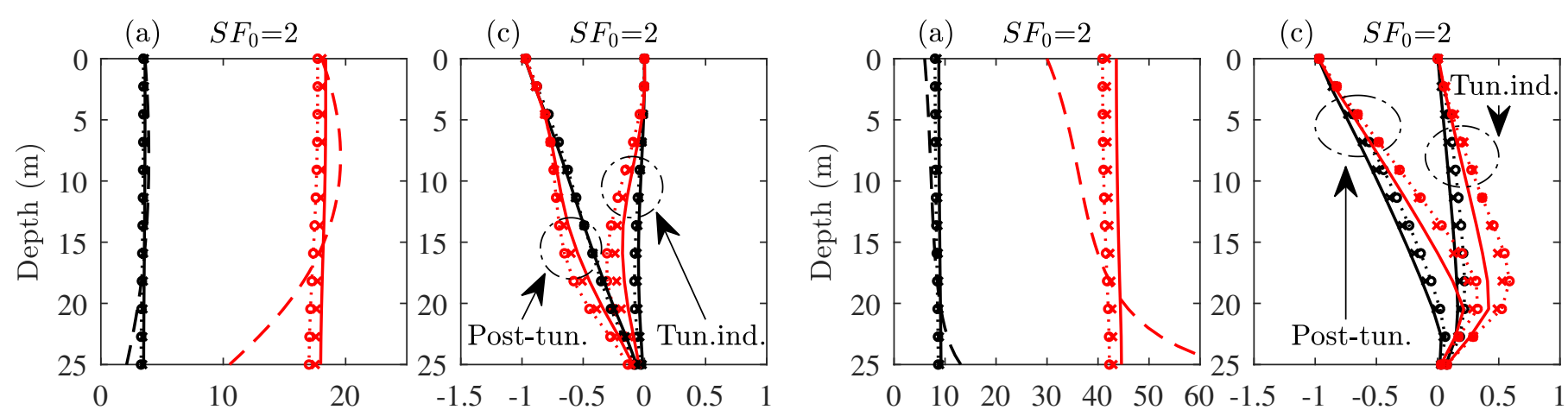

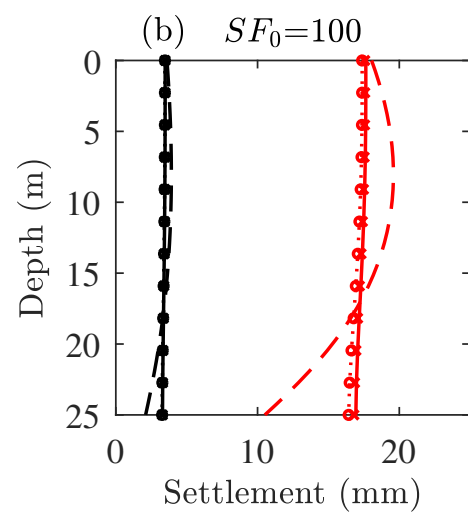

\begin{tabular}{cc} 
Settlement $(\mathrm{mm})$ & $\begin{array}{c}\text { Axial force }(\mathrm{MN}) \\
\text { Style }\end{array}$ \\
Colour & $---\mathrm{GF}$ \\
\hline$V_{l, t}=1 \%$ & $\cdots \cdots \cdots \mathrm{EP}\left(R_{f}=0\right)$ \\
\hline$V_{l, t}=5 \%$ & $\times \quad \operatorname{NEP}\left(R_{f}=0.75\right)$ \\
&
\end{tabular}

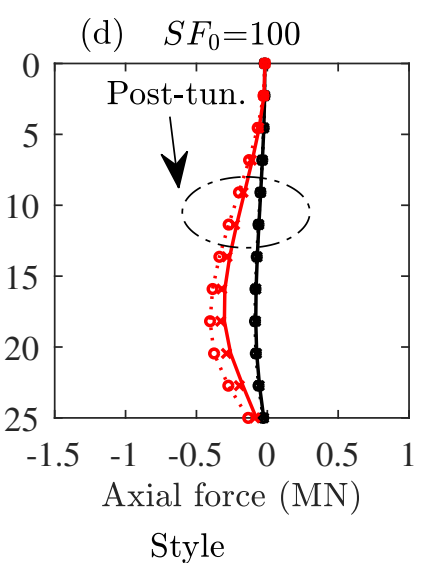

Fig. 5. Axial response for tunnel-pile offset of 15m: (a)-(b) tunnelling-induced settlements; (c)-(d) tunnelling-induced and post-tunnelling force profiles.

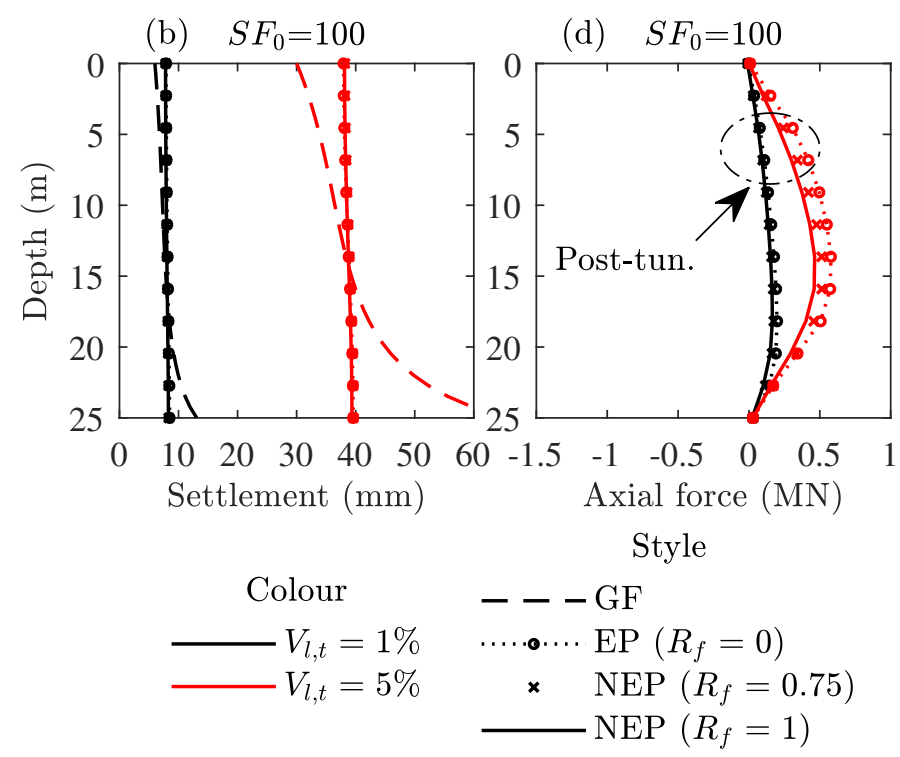

Fig. 6. Axial response for tunnel-pile offset of zero: (a)-(b) tunnelling-induced settlements; (c)-(d) tunnelling-induced and post-tunnelling force profiles. 


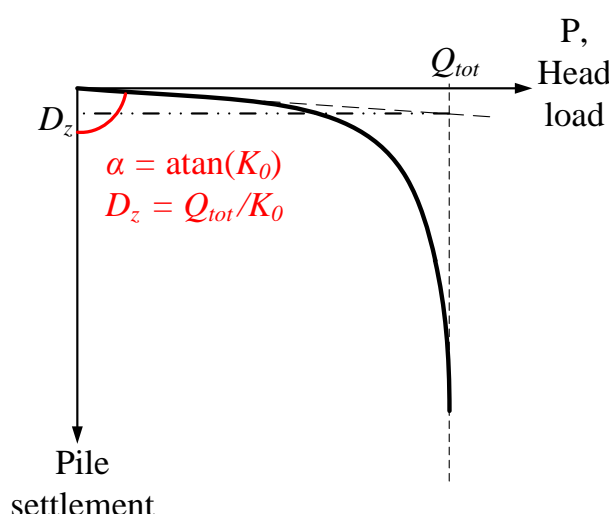

settlement (a)

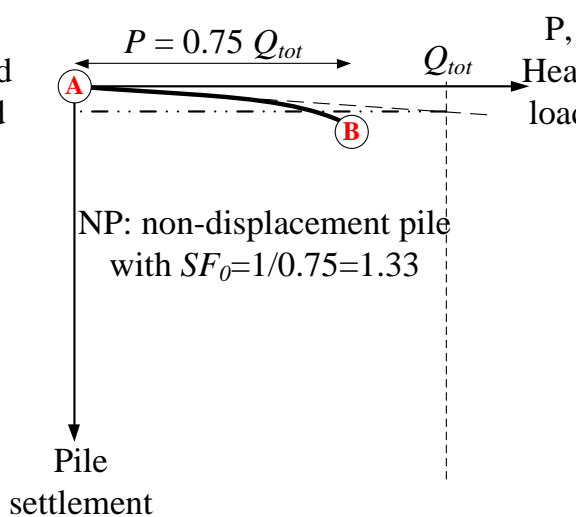

(b)

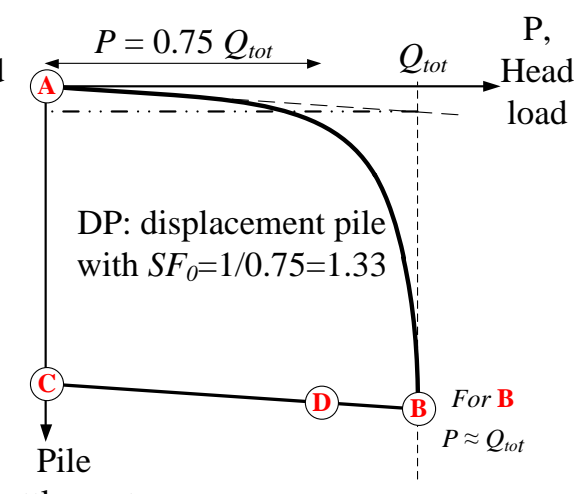

settlement (c)

Fig. 7. Conceptual sketches of pre-tunnelling pile loading: (a) pile head load-settlement curve and the definition of the settlement $D_{z}$; pre-excavation loading sequence of (b) non-displacement and (c) displacement piles. 

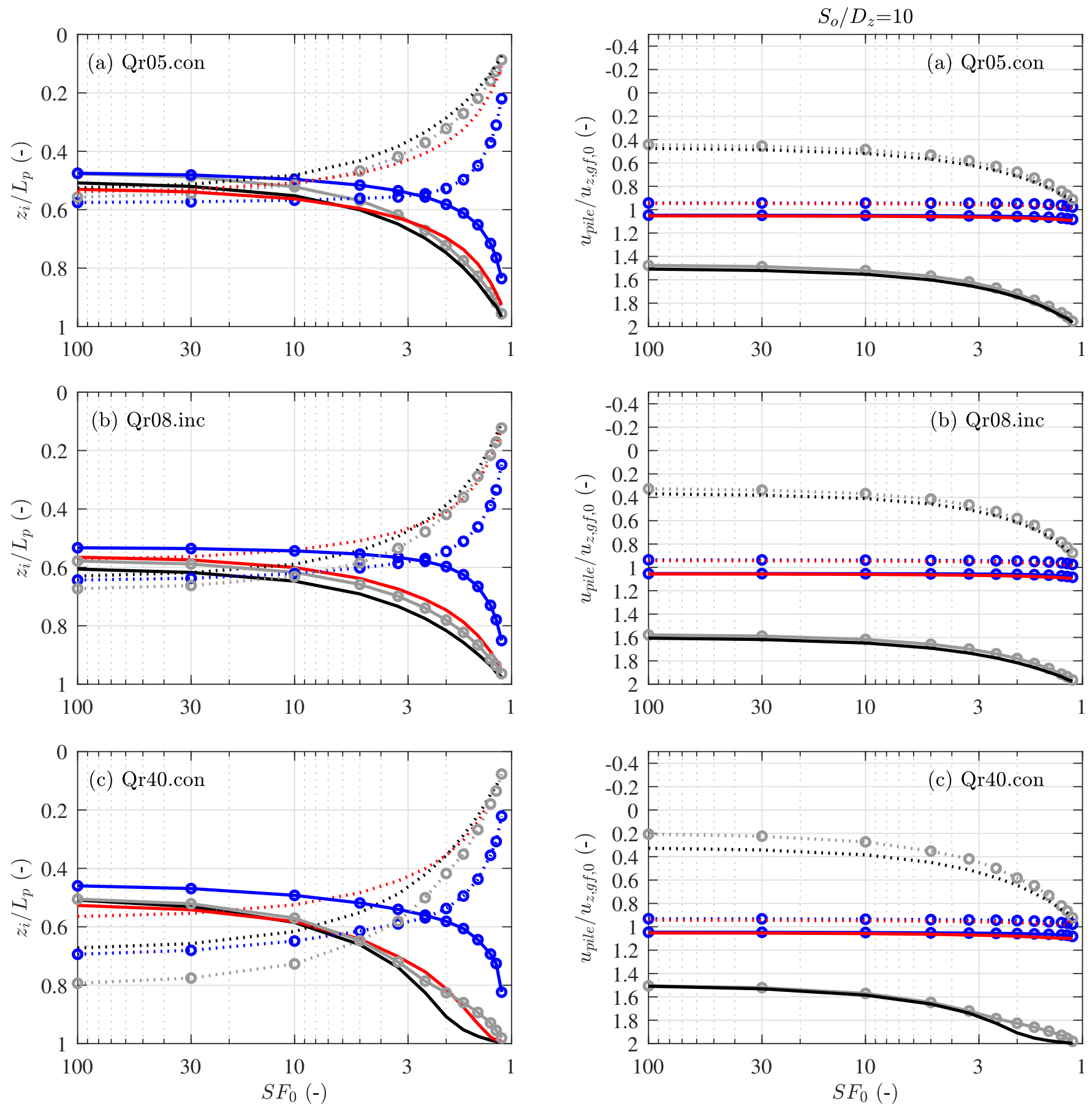

$u_{z, g f}$ decreasing with $z \quad u_{z, g f}$ increasing with $z$

$\cdots$ … DP. $\Delta S / D_{z}=10 \simeq$ DP. $\Delta S / D_{z}=-10$

…… DP. $\Delta S / D_{z}=1 \quad \longrightarrow$ DP. $\Delta S / D_{z}=-1$

…..... NP. $\Delta S / D_{z}=10 \longrightarrow$ NP. $\Delta S / D_{z}=-10$

NP. $\Delta S / D_{z}=1 \quad$ NP. $\Delta S / D_{z}=-1$

Fig. 8. Normalised interaction level depth $\left(z_{i} / L_{p}\right)$ for varying pile safety factor and greenfield profiles.

Fig. 9. Ratio between pile and greenfield surface settlements: inferred from Figure 8 by assuming $S_{0}=10 D_{z}$. 

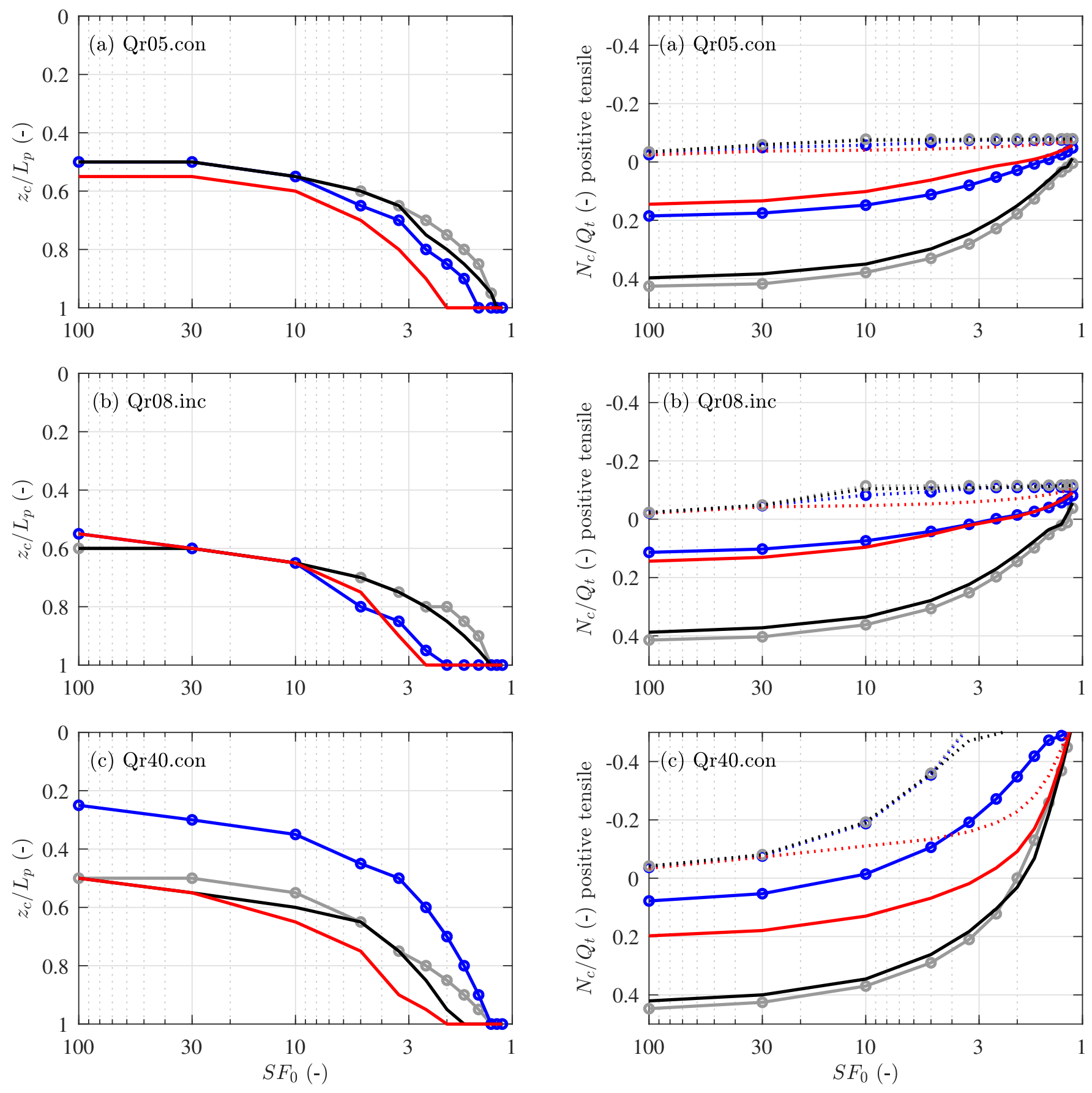

$u_{z, g f}$ increasing with $z$

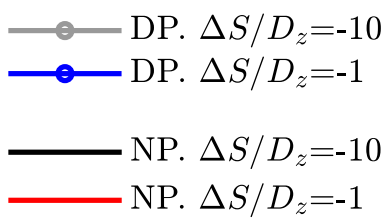

$u_{z, g f}$ decreasing with $z \quad u_{z, g f}$ increasing with $z$

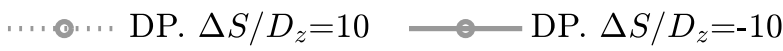

$\cdots \bullet \cdots$ DP. $\Delta S / D_{z}=1 \longrightarrow$ DP. $\Delta S / D_{z}=-1$

…..... NP. $\Delta S / D_{z}=10 \longrightarrow$ NP. $\Delta S / D_{z}=-10$

NP. $\Delta S / D_{z}=1$ NP. $\Delta S / D_{z}=-1$

Fig. 10. Critical level depth $\left(z_{c} / L_{p}\right)$.

Fig. 11. Post-tunnelling critical axial force $\left(N_{c} / Q_{t}\right)$. 


\section{FIGURES}

LIST OF TABLES

4641 Considered scenarios: main analyses (top half) and supplemental analyses (bottom half) . . . . . . . . 
TABLES

Table 1. Considered scenarios: main analyses (top half) and supplemental analyses (bottom half).

\begin{tabular}{lccccccccl}
\hline Label & $d_{p}$ & $L / d_{p}$ & $\tau_{f}(0)$ & $\tau_{f}\left(L_{p}\right)$ & $q_{b, f}$ & $D_{z}$ & $\frac{\tau_{f}\left(L_{p}\right)}{\tau_{f}(0)}$ & $Q_{r}=\frac{Q_{b}}{Q_{t o t}}$ & Supplemental \\
& $(\mathrm{m})$ & $(-)$ & $(\mathrm{kPa})$ & $(\mathrm{kPa})$ & $(\mathrm{kPa})$ & $(\mathrm{mm})$ & $(-)$ & $(-)$ & Label \\
\hline Qr05.con & 0.5 & 40 & 60 & 60 & $9 \times 60$ & 9.0 & 1 & $5 \%$ & FL.LD40.con \\
Qr08.inc & 0.5 & 40 & 30 & 90 & $9 \times 90$ & 9.7 & 3 & $8 \%$ & FL.LD40.inc \\
Qr40.con & 0.5 & 40 & 5 & 5 & $9 \times 60$ & 1.3 & 1 & $40 \%$ & CO.LD40.con \\
\hline & 0.5 & 40 & 60 & 60 & 0 & 9.0 & 1 & $0 \%$ & FR.LD40.con \\
& 0.5 & 40 & 30 & 90 & 0 & 9.4 & 3 & $0 \%$ & FR.LD40.inc \\
& 0.5 & 10 & 60 & 60 & $9 \times 60$ & 6.0 & 1 & $0 \%$ & FR.LD10.con \\
& 0.5 & 10 & 60 & 60 & $9 \times 60$ & 7.4 & 1 & $18 \%$ & FL.LD10.con \\
\hline
\end{tabular}


SUPPLEMENTAL DATA 
LIST OF FIGURES 

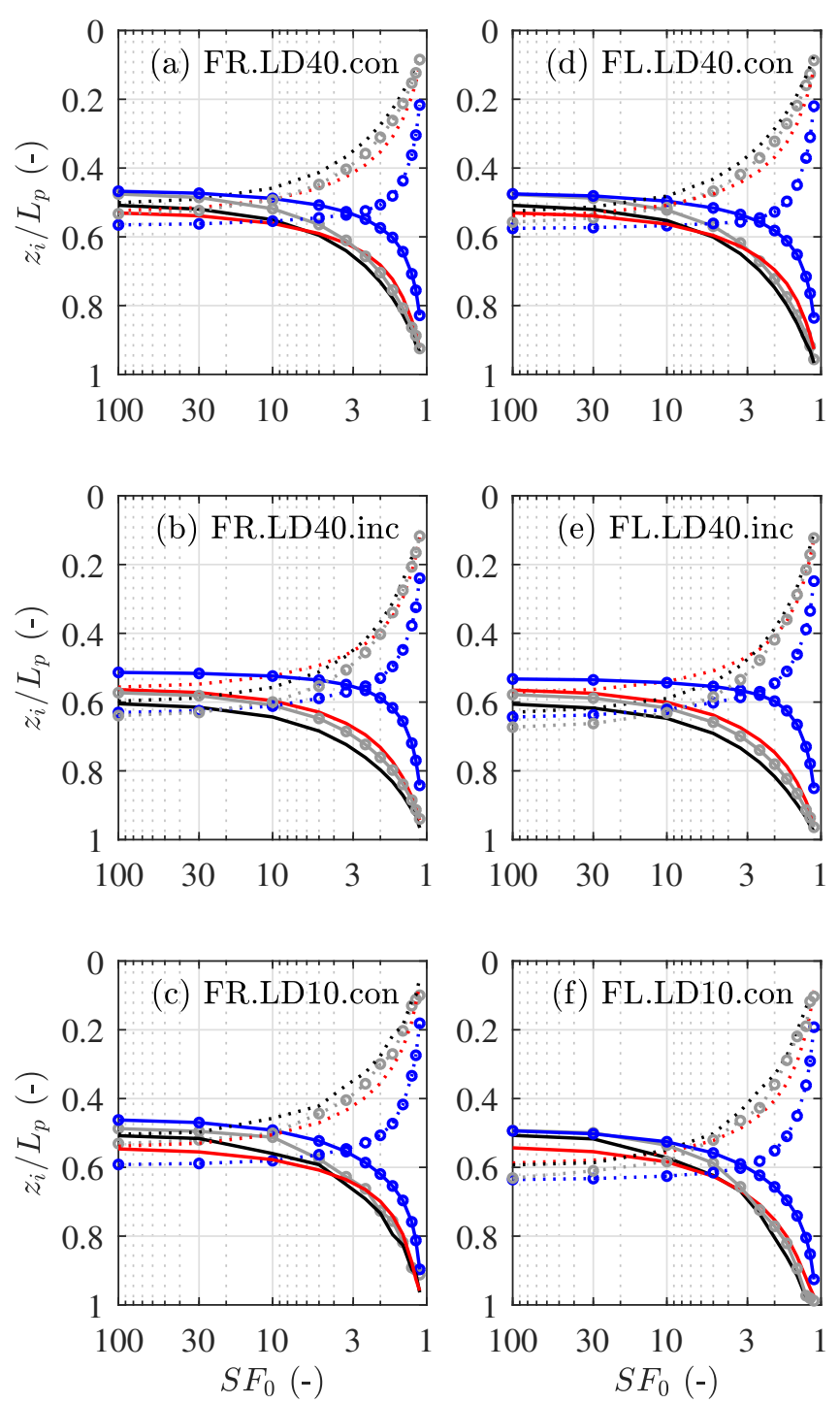

$u_{z, g f}$ decreasing with $z$

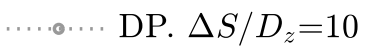

$\cdots \cdots \cdots$ DP. $\Delta S / D_{z}=1$

NP. $\Delta S / D_{z}=10$

NP. $\Delta S / D_{z}=1$

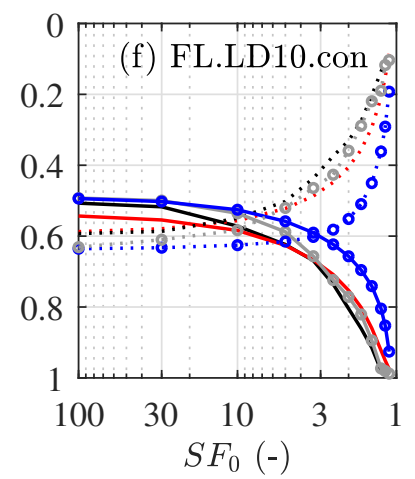

$u_{z, g f}$ increasing with $z$

$$
\begin{aligned}
& \longrightarrow \text { DP. } \Delta S / D_{z}=-10 \\
& \text { DP. } \Delta S / D_{z}=-1 \\
& \text { NP. } \Delta S / D_{z}=-10 \\
& \text { NP. } \Delta S / D_{z}=-1
\end{aligned}
$$

Fig. S1. [Supplemental data] Normalised interaction level depth $\left(z_{i} / L_{p}\right)$.
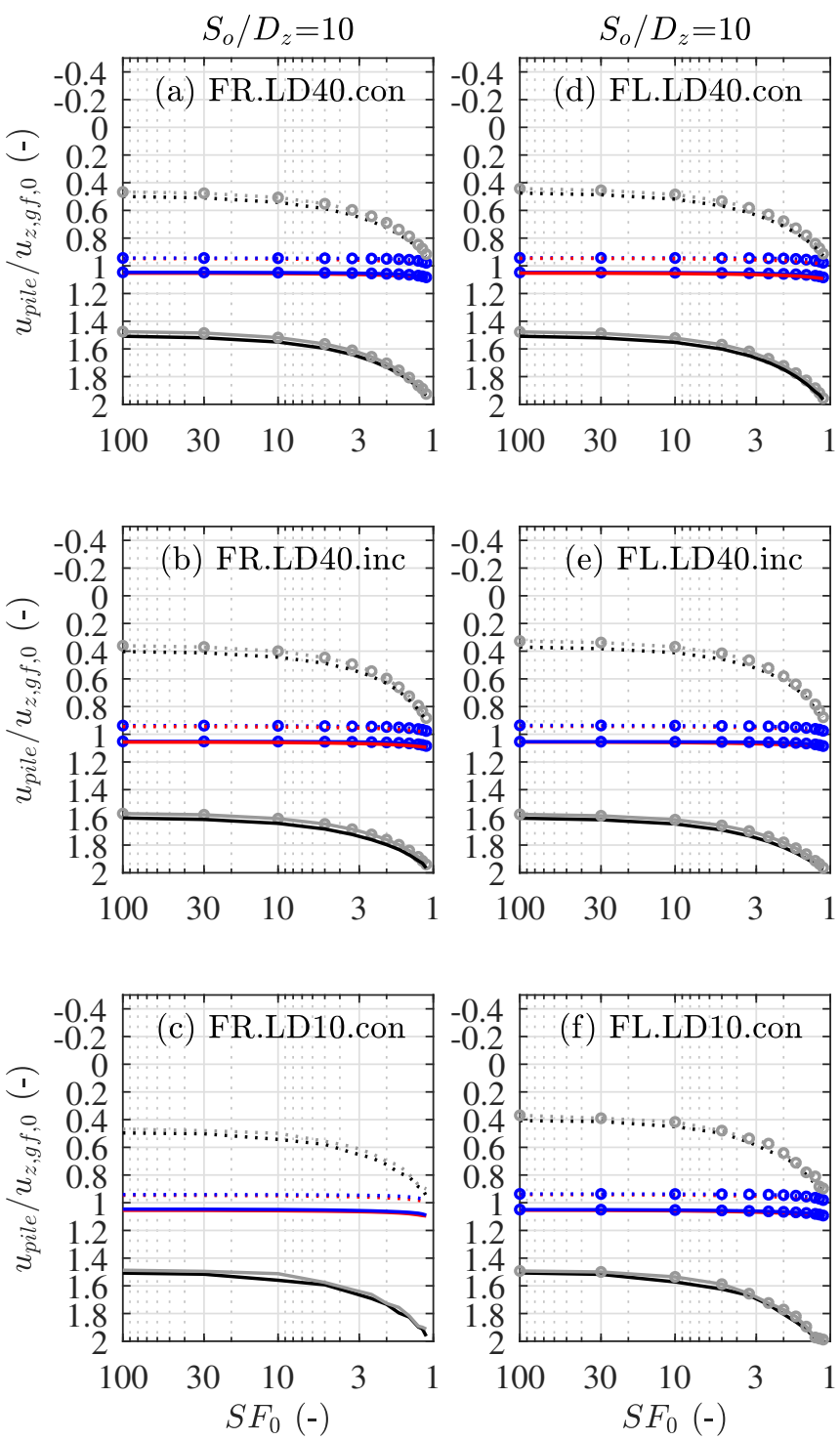

$u_{z, g f}$ decreasing with $z$

$u_{z, g f}$ increasing with $z$

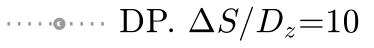

$\cdots \cdots \cdots$ DP. $\Delta S / D_{z}=1$

NP. $\Delta S / D_{z}=10$

$\longrightarrow$ DP. $\Delta S / D_{z}=-10$

NP. $\Delta S / D_{z}=1$

DP. $\Delta S / D_{z}=-1$

NP. $\Delta S / D_{z}=-10$

NP. $\Delta S / D_{z}=-1$

Fig. S2. [Supplemental data] Ratio between pile and greenfield surface settlements. 

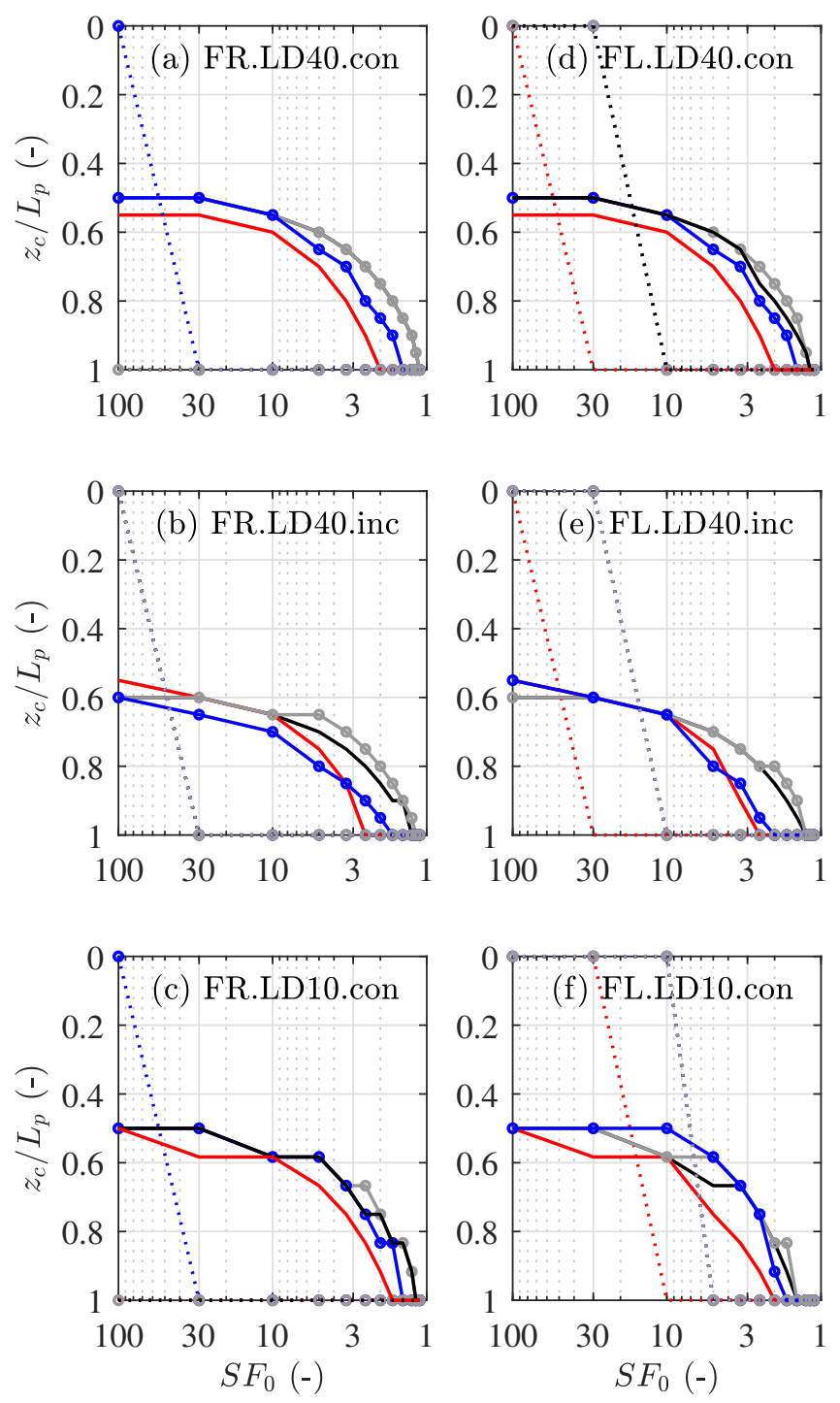

$u_{z, g f}$ decreasing with $z$

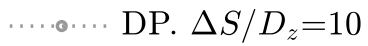

....... DP. $\Delta S / D_{z}=1$

….... NP. $\Delta S / D_{z}=10$

NP. $\Delta S / D_{z}=1$

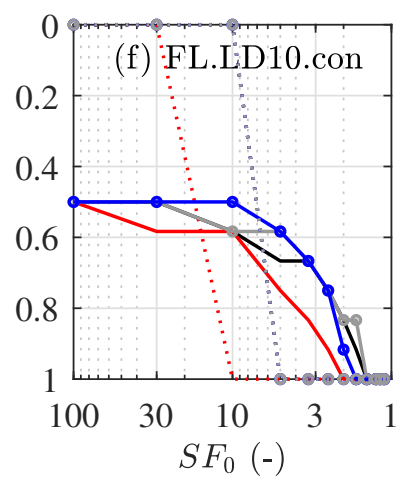

$u_{z, g f}$ increasing with $z$

$\longrightarrow$ DP. $\Delta S / D_{z}=-10$

DP. $\Delta S / D_{z}=-1$

NP. $\Delta S / D_{z}=-10$

NP. $\Delta S / D_{z}=-1$

Fig. S3. [Supplemental data] Critical level depth $\left(z_{c} / L_{p}\right)$.
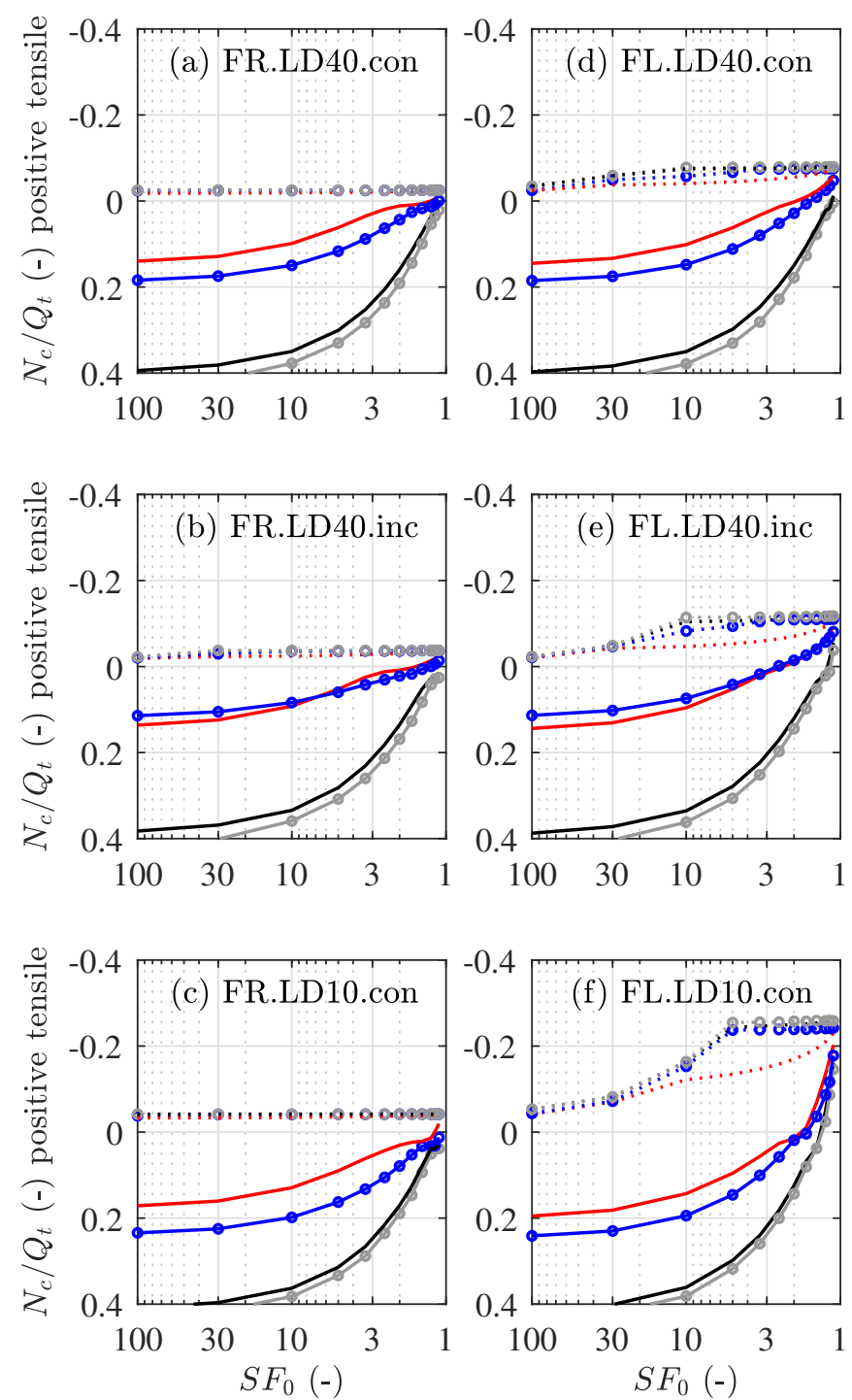

$u_{z, g f}$ decreasing with $z$

$u_{z, g f}$ increasing with $z$

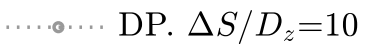

$\longrightarrow$ DP. $\Delta S / D_{z}=-10$

…… DP. $\Delta S / D_{z}=1$

DP. $\Delta S / D_{z}=-1$

NP. $\Delta S / D_{z}=10$

NP. $\Delta S / D_{z}=1$

NP. $\Delta S / D_{z}=-10$

NP. $\Delta S / D_{z}=-1$

Fig. S4. [Supplemental data] Post-tunnelling critical axial force $\left(N_{c} / Q_{t}\right)$. 